\title{
SUDDEN DISTURBANCES OF THE IONOSPHERE
}

\author{
By John Howard Dellinger
}

\begin{abstract}
The phenomenon described in this paper is the occurrence of a very sudden change in ionization of a portion of the ionosphere. It manifests itself by the complete fading out of high-frequency radio transmission for a period of a few minutes to an hour or more and by perturbations of terrestrial magnetism and earth currents. The effect was discovered in 1935, and it was found to occur simultaneously everywhere throughout the illuminated half of the globe but not in the night half. The results of a world-wide investigation of the phenomenon, which followed this discovery, are presented in this paper.

The radio and magnetic effects have been shown to be of a distinct type, quite different from previously known vagaries in these fields. They are of maximum intensity in that region of the earth where the sun's radiation is perpendicular.

Many of the occurrences are simultaneous with great eruptions on the sun. Such eruptions emit vast quantities of ultraviolet light. These radiations are sometimes of such frequencies as to cause intense ionization of part of the ionosphere below the $E$ layer. This sudden ionization causes the radio and other perturbations. Their characteristics are explained. Study of this effect is leading to new understanding of the nature of the ionosphere, the processes of radio-wave transmission, the mechanisms of terrestrial magnetism, and the phenomena occurring in the sun.
\end{abstract}

\section{CONTENTS}

Page

II. Data

III. Characteristies of the radio-transmission effects

1. Geographic simultaneity

2. Suddenness

3. Degree of intensity change

4. Frequencies affected

5. Geographic distribution

IV. Characteristics of the terrestrial magnetic and earth-current effects

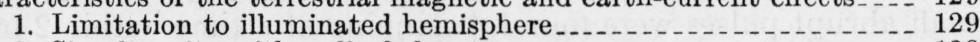

2. Simultaneity with radio fadeouts

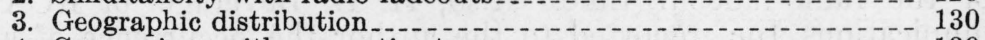

4. Comparison with magnetic storms

V. Solar phenomena associated with sudden ionosphere disturbances.... 131

1. Exactness of simultaneity

2. Proportionate number of simultaneous occurrences

3. Character of eruptions

4. Location of eruptions on sun

5. Recurrence tendency

6. Relation to sunspots.

VI. Discussion and explanation

1. Seat of the disturbances deduced from radio effects

2. Magnetic effects ........... 137

3. Solar source

VII. Bibliography 


\section{INTRODUCTION}

This paper presents the conclusions and data up to the end of 1936 of an investigation, started about the middle of 1935, of a hitherto unknown phenomenon. The phenomenon is the occurrence of a sudden intense increase in the ionization of a part of the earth's upper atmosphere, with resultant transient disturbances in such phenomena as radio-wave transmission, terrestrial magnetism, and earth currents. The radio effect is of serious practical import, as it manifests itself principally as a sudden disappearance of radio signals received on high frequencies, the period of silence ranging from a few minutes to an hour or more. The whole phenomenon is of scientific interest particularly because it appears to have its origin in sudden bursts of radiation from the sun, and it is opening the way to increased understanding of the sun, the ionosphere, radio transmission, terrestrial magnetism, and related phenomena.

In October 1935 the author reported ${ }^{1}$ the occurrence of radio fadeouts on March 20, May 12, July 6, and August 30 of that year. He pointed out that they occurred throughout the illuminated half of the globe but not the dark half, advanced the hypothesis that they depend on some solar emanation lasting only a few minutes, and suggested observations by workers in other sciences with a view to learning of the possible occurrence of effects in terrestrial magnetism, earth currents, solar radiation, etc., simultaneous with radio fadeouts. The suggestion met with widespread interest, and the author has had the collaboration of numerous individuals and organizations in this investigation.

Evidence followed rapidly that the postulated simultaneous effects do occur. The astronomers at Mt. Wilson Observatory of the Carnegie Institution of Washington were asked to examine their spectrohelioscopic data for the dates in question, and in November 1935, R. S. Richardson of that Observatory informed the author that on July 6 and August 30 bright eruptions had been observed on the sun within a few minutes of the times of the radio fadeouts, and on the other two dates no observations had been made at the times of the fadeouts. These results were announced by Dr. Richardson and the author at the end of 1935 .

The magnetograms of the Cheltenham, Md., Observatory of the U. S. Coast and Geodetic Survey were examined by the author for the times of all the fadeouts then known, and for several of them small abrupt pulses were found, beginning at a time within 2 minutes of the radio-fadeout time. Also, $\mathrm{H}$. H. Beverage, of RCA Communications, Inc., reported to the author the occurrence of a large, sharp pulse on an earth-current recorder within a few minutes of the time of several of the radio fadeouts.

From these beginnings has grown an extensive research upon these interrelated phenomena. Through the kindness of many cordial cooperators the author is able to present a summary of data on the known occurrences. Acknowledgments of the work of these cooperators are given on p.140. Systematic recording of the phenomena has been carried on by the National Bureau of Standards, and complete reports have been furnished by a few other groups, but many of the reports from scattered places are sporadic and partial. Data are relatively meager for the

I See first two citations in section VII, Bibliography. 
Asiatic and Pacific regions. It is believed that the results are of sufficient value to provide encouragement for more widespread and systematic observations and for more intensive exploration of the several fields of inquiry opened up by this work.

Preliminary reports of the results, and explanation in terms of ionosphere effects, were given by the author in papers presented at the Washington meeting of the American Section, International Scientific Radio Union, May 1, 1936, and at the Cleveland Convention of the Institute of Radio Engineers, May 11, 1936. A number of brief papers have been published by the author and others, giving some of the results and preliminary conclusions (see section VII, Bibliography).

This paper presents a compressed summary of the known facts regarding 118 sudden disturbances of the ionosphere, many of which were accompanied by solar eruptions, many of which were manifested by perturbations of terrestrial magnetism and earth currents, and each of which was manifested by the wiping out of hundreds or thousands of radio transmissions.

\section{DATA}

In this section a summary of the available data is presented. In sections III, IV, and V the facts regarding particular aspects of the data are presented and discussed. In section VI is given a discussion and explanation of the entire phenomenon.

The data considered in this paper are given in very condensed form in table 1 and are essentially for the years 1935 and 1936. One earlier occurrence is included, that of Nov. 28, 1934, as it was clearly the same phenomenon. There is little reliable information on earlier occurrences of this type. Some records indicate occurrences which may or may not be the same phenomenon. Thus, the logs of radio operating companies show radio traffic interruptions on many occasions in 1934 and earlier, but there is very little information at hand to judge whether they were of the type due to the sudden ionosphere disturbances here studied or to others of the various radio wave vagaries mentioned at the beginning of section III, page 125. Information on a number of such traffic interruptions occurring in 1928 is given in an article by T. L. Eckersley. ${ }^{2}$ From the data given in that paper, the failure of radio transmission on October 10, 1928, from 1100 to 1200 GMT, may have been a case of the phenomenon here studied. Likewise, from data reported to the author of the present paper, the failure of radio transmission from 1305 to 1400 GMT on May 11, 1934, may also have been a case.

Similarly, there is some information on a few early occurrences of sudden terrestrial magnetic pulses simultaneous with visible solar eruptions, occasionally reported by astronomers many years ago. Some instances are given in an article by G. E. Hale, ${ }^{3}$ and interesting ones were observed on August 3 and 5, 1872, by C. A. Young, as described in his book. ${ }^{4}$ These occurrences may have been of the type associated with the sudden ionosphere disturbances here studied.

2 An investigation of short waves, J. Inst. Elec. Engrs. (London) 67, 992 (1929).

3 The spectrohelioscope and its work, pt. S, Solür eruptions and their apparent terrestrial effects. Astrophys. J. 73, 379 (1931).

The Sun (1834). 
TABLE 1.-Data on radio fadeouts and other manifestations of sudden ionosphere disturbances

\begin{tabular}{|c|c|c|c|c|}
\hline Date & Time, GMT & Reported observed in & $\begin{array}{l}\text { Reported locations of } \\
\text { transmitting stations }\end{array}$ & $\begin{array}{l}\text { Reported solar and mag- } \\
\text { netic effects, etc. }\end{array}$ \\
\hline \multirow{3}{*}{$\begin{array}{c}1934 \\
\text { Nov. } 28\end{array}$} & & & \multirow{3}{*}{$\begin{array}{l}\text { Eastern United States } \\
\text { of America. } \\
\text { South America...... } \\
\text { District of Columbia }\end{array}$} & \multirow{3}{*}{$\begin{array}{l}\text { Solar eruption, begin- } \\
\text { ning about } 1710 \text {. Ter } \\
\text { mag pulse, } 1707 \text { to } \\
1730 \text {. Earth-current } \\
\text { pulse, } 1710 \text { to } 1740 \text {. }\end{array}$} \\
\hline & 1710 to 1740 & Georgia $\ldots . . . . . . . .$. & & \\
\hline & $\begin{array}{l}1710 \text { to } 1745 \\
1710 \text { to } 1730-\end{array}$ & $\begin{array}{l}\text { New York } \\
\text { District of Columbia. }\end{array}$ & & \\
\hline $\begin{array}{l}1935 \\
\text { Jan. } 25\end{array}$ & 0335 to $0535 \ldots$ & California............ & Asia, Philippines, Java_.- & \\
\hline Mar. 20 & $\begin{array}{l}0150 \text { to } 0200 \\
0148 \text { to } 0200\end{array}$ & $\begin{array}{l}\text { Philippines................ } \\
\text { California......... }\end{array}$ & $\begin{array}{l}\text { California } \\
\text { Asia, Philippines, Java.- }\end{array}$ & \\
\hline May 12 & $\begin{array}{l}1157 \text { to } 1215 \\
1156 \text { to } 1214- \\
1200 \text { to } 1215\end{array}$ & $\begin{array}{l}\text { France } \\
\text { New Jersey } \\
\text { New York }\end{array}$ & $\begin{array}{l}\text { Numerous } \\
\text { England } \\
\text { Europe, South America. }\end{array}$ & Ter mag pulse, 1157 \\
\hline July & 1409 to $1437 \ldots 08$ to 1430 & 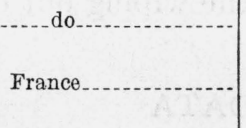 & $\begin{array}{l}\text { England, United States } \\
\text { of America, South } \\
\text { America. } \\
\text { North and S outb } \\
\text { America, Asia. }\end{array}$ & $\begin{array}{l}\text { Solar eruption, } 1358 \text { to } \\
1418 . \text { Ter mag pulse, } \\
1407 \text { to } 1412 \text {. Earth } \\
\text { current pulse, } 1400 \text { to } \\
1411 .\end{array}$ \\
\hline Aug. 30 & $\begin{array}{l}2320 \text { to } 2325 \text { to } 2335 \\
2300 \text { to } 2329\end{array}$ & Philippines............ & $\begin{array}{l}\text { Asia, Philippines, Java, } \\
\text { WesternUnited States } \\
\text { of America. } \\
\text { California............... }\end{array}$ & $\begin{array}{l}\text { Solar eruption } 2312 \text { to } \\
\text { after } 2330 \text {. }\end{array}$ \\
\hline Sept. 13 & 1630 to 1640 to 1650. & California... & $\begin{array}{l}\text { United States of Amer- } \\
\text { ica, Manila, Shanghai, } \\
\text { Tokyo. }\end{array}$ & $\begin{array}{l}\text { Solar eruption, } 1635 \text { to } \\
1641 \text {. Ter mag pulse, } \\
1630 \text {. }\end{array}$ \\
\hline Sept. 27 & $\begin{array}{l}1250 \text { to } 1350 \\
1245 \text { to } 1315\end{array}$ & $\begin{array}{l}\text { New York....... } \\
\text { England }\end{array}$ & $\begin{array}{l}\text { Europe, South America } \\
\text { Numerous. }\end{array}$ & $\left\{\begin{array}{c}\text { Solar eruption, from be- } \\
\text { fore } 1200 \text { to after } 1230 . \\
\text { Ter mag pulse, } 1250 .\end{array}\right.$ \\
\hline Sept. 29 & 2055 to 2120 to 0150 & California... & $\begin{array}{l}\text { Tokyo, Shanghai, Ha- } \\
\text { waii, New York. }\end{array}$ & \\
\hline & 2050 to 2110 & District of Columbia. & Massachusetts . . ........... & \\
\hline Oct. 24 & 1100 to 1200 & New York . . . . & Numerous....... & $\begin{array}{l}\text { Earth-current pulse, } \\
1130 \text { to } 1215 .\end{array}$ \\
\hline Nov. 18 & 1755 to 1815 & Puerto Rico..... & United States of Amer- & \\
\hline & 1757 to 1800 & District of Columbia. & & \\
\hline Nov. $2 \theta$ & 1405 to 1415 & $\begin{array}{l}\text { New York... } \\
\text { Brazil. }\end{array}$ & $\begin{array}{l}\text { South America } \\
\text { All stations. }\end{array}$ & $\begin{array}{l}\text { Solar eruption, from be- } \\
\text { fore } 1431 \text { to } 1445 \text {. }\end{array}$ \\
\hline Nov. 30 & 1721 to 1730 to $1815_{--}$ & District of Columbia & Ohio, Massachusetts.... & $\begin{array}{l}\text { Solar eruption, } 1751 \text { to } \\
1830 \text {. }\end{array}$ \\
\hline Nov. 30 & $\begin{array}{l}1850 \text { to } 1908 \text { to } 1930 \\
1900 \text { to } 1925 \text { to } 1935 .-\end{array}$ & Hawaii & California & \\
\hline Dec. 16 & $\begin{array}{l}2209 \text { to } 2230 \\
2223 \text { to } 2225\end{array}$ & $\begin{array}{l}\text { District of Columbia } \\
\text { Hawaii-........... }\end{array}$ & 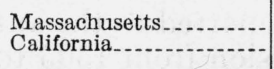 & $\left\{\begin{array}{l}\text { Solar eruption, } 2210 \text { to } \\
2238 \text {. }\end{array}\right.$ \\
\hline Dec. 17 & $\begin{array}{l}1615 \text { to } 1630 \\
1630 \text { to } 1700-18 \text { to } 1630 .- \\
1610 \text { to } 1618 \\
1620 \text { to } 1630 \text { to } 1655 .-\end{array}$ & $\begin{array}{l}\text { New York........... } \\
\text { New Jersey } \\
\text { District of Columbia. } \\
\text { Texas................... }\end{array}$ & $\begin{array}{l}\text { South America } \\
\text { England } \\
\text { Massachusetts, Ohio...- } \\
\text { Numerous amateur sta- } \\
\text { tions. }\end{array}$ & $\begin{array}{l}\text { Solar eruption, begin- } \\
\text { ning before } 1609 \text {. Ter } \\
\text { mag pulse, } 1610 \text { to } \\
1630 \text {. }\end{array}$ \\
\hline Dec. 18 & 0450 to 0615 & California................ & Asia, Philippines, Java & \\
\hline Dec. 23 & $\begin{array}{l}1730 \text { to } 1826 \text { to } 2000 \\
1730 \text { to } 2000 \\
1730 \text { to } 1930 \\
1740 \text { to } 1930 \\
1745\end{array}$ & $\begin{array}{l}\text { District of Columbia } \\
\text { California } \\
\text { New York } \\
\text { Georgia............... } \\
\text { Puerto Rico }\end{array}$ & $\begin{array}{l}\text { Ohio, Massachusetts, } \\
\text { District of Columbia. } \\
\text { Asia, Philippines, Java } \\
\text { Europe, South America } \\
\text { Eastern United States } \\
\text { of America. } \\
\text { United States of Americal }\end{array}$ & $\begin{array}{l}\text { Solar eruption, from be- } \\
\text { fore } 1757 \text { to after } 1805 .\end{array}$ \\
\hline
\end{tabular}

'Disappearance or weakening of sky-waves reflected vertically from ionosphere. 
TABLE 1.-Data on radio fadeouts and other manifestations of sudden ionosphere disturbances-Continued

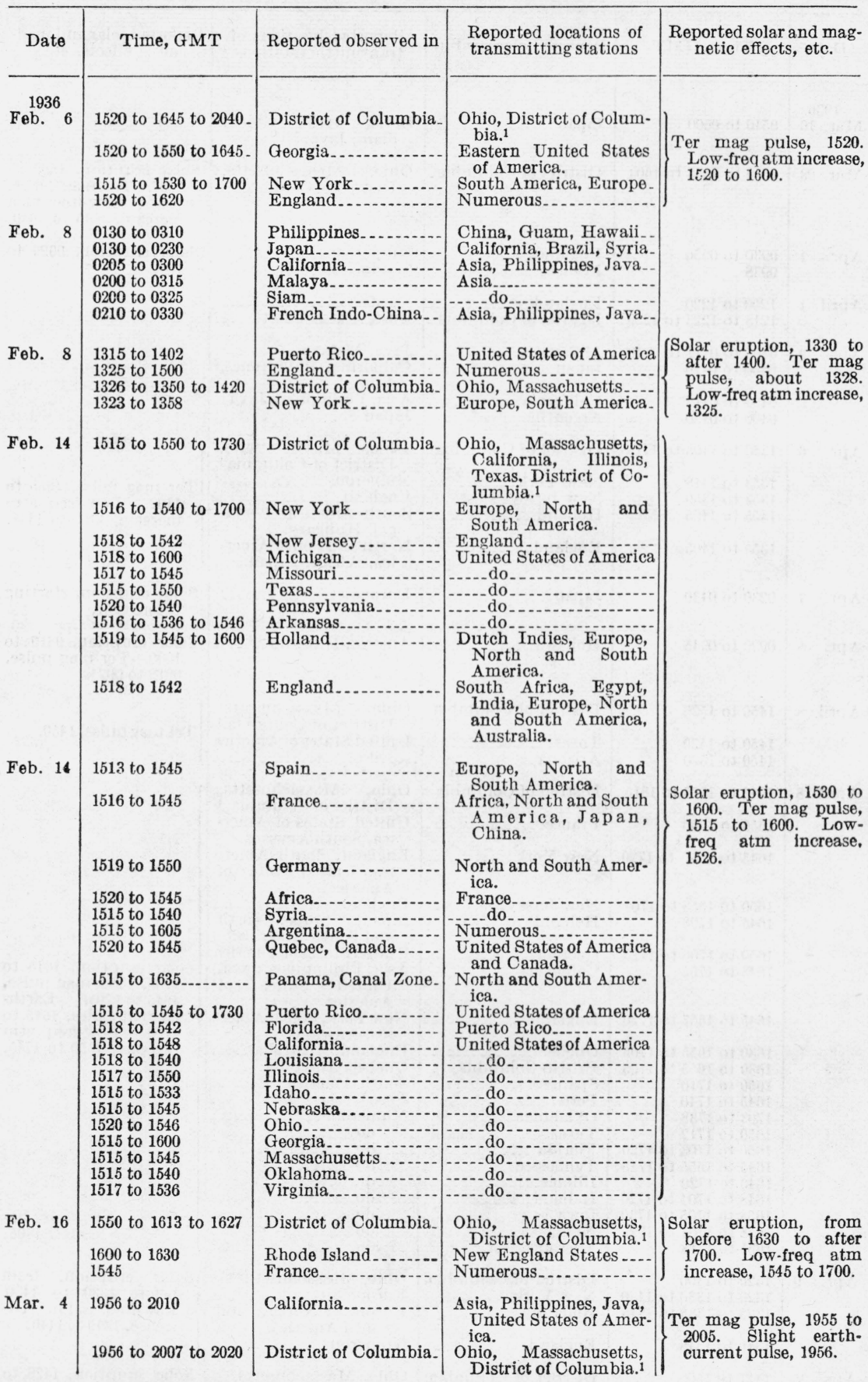

${ }_{1}^{1}$ Disappearance or weakening of sky-waves reflected vertically from ionosphere. 
TABLE 1.-Data on radio fadeouts and other manifestations of sudden ionosphere disturbances-Continued

\begin{tabular}{|c|c|c|c|c|}
\hline Date & Time, GMT & Reported observed in & $\begin{array}{l}\text { Reported locations of } \\
\text { transmitting stations }\end{array}$ & $\begin{array}{l}\text { Reported solar and mag- } \\
\text { netic effects, etc. }\end{array}$ \\
\hline $\begin{array}{c}1936 \\
\text { Mar. } 10\end{array}$ & 0540 to 0600 & Japan...... & $\begin{array}{l}\text { India, Syria, China, } \\
\text { Siam, Java. }\end{array}$ & \\
\hline Mar. 23 & 1545 to 1553 to 1603 . & District of Columbia & $\begin{array}{l}\text { Ohio, Massachusetts, } \\
\text { District of Columbia }{ }^{1}\end{array}$ & $\begin{array}{l}\text { Solar eruption, } 1530 \text { to } \\
1607 \text {. Ter mag pulse, } \\
1545 \text {. Low-freq atm } \\
\text { increase, } 1545 \text { to } 1650 .\end{array}$ \\
\hline Apr. 1 & $\begin{array}{l}0930 \text { to } 0950 \\
0938\end{array}$ & $\begin{array}{l}\text { England } \\
\text { France..... }\end{array}$ & Numerous & $\begin{array}{l}\text { Solar eruption, } 0926 \text { to } \\
1040 .\end{array}$ \\
\hline April 1 & $\begin{array}{l}1200 \text { to } 1220 \\
1218 \text { to } 1223 \text { to } 1229 \text {. }\end{array}$ & $\begin{array}{l}\text { England } \\
\text { District of Columbia }\end{array}$ & Ohio, Massachusetts ... & \\
\hline Apr. 2 & $\begin{array}{l}0405 \text { to } 0417 \text { to } 0640 \text {. } \\
0400 \text { to } 0420 \\
0400 \text { to } 0415 \text {. } \\
0400 \text { to } 0420\end{array}$ & $\begin{array}{l}\text { Malaya } \\
\text { Japan } \\
\text { California............ } \\
\text { Argentine... }\end{array}$ & $\begin{array}{l}\text { Java, Malaya } \\
\text { California, Philippines, } \\
\text { Asia. } \\
\text { Asia, Philippines, Java .-. } \\
\text { Japan........................ }\end{array}$ & \\
\hline Apr. & $\begin{array}{l}1356 \text { to } 1403 \text { to } 1418 \\
1353 \text { to } 1418 \\
1353 \text { to } 1359 \\
1355 \text { to } 1405 \\
1355 \text { to } 1405\end{array}$ & $\begin{array}{l}\text { District of Columbia. } \\
\text { New York.. } \\
\text { New Jersey } \\
\text { Holland } \\
\text { England }\end{array}$ & $\begin{array}{l}\text { Ohio, Massachusetts, } \\
\text { District of Columbia } 1 \\
\text { Numerous. } \\
\text { England } \\
\text { South America, Portu- } \\
\text { gal, Hungary. } \\
\text { North and South Amer- } \\
\text { ica, Africa, Japan. }\end{array}$ & $\left\{\begin{array}{l}\text { Ter mag pulse, } 1355 \text { to } \\
1402 \text {. Low-freq atm } \\
\text { increase, } 1357 \text { to } 1448 .\end{array}\right.$ \\
\hline Apr. 7 & 0230 to 0430 & Japan & Europe & $\begin{array}{l}\text { Solar eruption, starting } \\
\text { before } 0231 \text {. }\end{array}$ \\
\hline Apr. & 0920 to 0945 & Holland.... & Austria, Hungary... & $\begin{array}{l}\text { Solar eruption, } 0810 \text { to } \\
1000 \text {. Ter mag pulse, } \\
0912 \text { to } 0925 \text {. }\end{array}$ \\
\hline April 8 & $\begin{array}{l}1450 \text { to } 1520 \\
1450 \text { to } 1520 \\
1450 \text { to } 1520\end{array}$ & $\begin{array}{l}\text { District of Columbia. } \\
\text { Texas } \\
\text { Arizona }\end{array}$ & $\begin{array}{c}\text { Ohio, Massachusetts, } \\
\text { District of Columbia. } \\
\text { United States of America }\end{array}$ & Ter mag pulse, 1450 . \\
\hline April 8 & $\begin{array}{l}1646 \text { to } 1726 \text { to } 1815 \text { - } \\
1650 \text { to } 1700 \\
1645 \text { to } 1657 \text { to } 1720 \\
1650 \text { to } 1658 \text { to } 1704 \\
1645 \text { to } 1708\end{array}$ & $\begin{array}{l}\text { District of Columbia } \\
\text { France } \\
\text { New York } \\
\text { New Jersey } \\
\text { Holland }\end{array}$ & $\begin{array}{l}\text { Ohio, Massachusetts, } \\
\text { District of Columbia. } 1 \\
\text { United States of Amer- } \\
\text { ica, South America. } \\
\text { England, South Amer- } \\
\text { ica, United States of } \\
\text { America. } \\
\text { England. } \\
\text { Japan, Europe, North } \\
\text { and South America. } \\
\text { United States of America }\end{array}$ & \\
\hline & $\begin{array}{l}1648 \text { to } 1705 \\
1645 \text { to } 1657 \text { to } 1720 \\
1630 \text { to } 1655 \text { to } 1705 \\
1630 \text { to } 1655 \text { to } 1705 \\
1650 \text { to } 1710 \\
1645 \text { to } 1740 \\
1703 \text { to } 1738 \\
1650 \text { to } 1712 \\
1650 \text { to } 1703 \text { to } 1720 \\
1645 \text { to } 1655 \text { to } 1715 \\
1640 \text { to } 1720 \\
1648 \text { to } 1704 \text { to } 1720 \\
1658 \text { to } 1705 \text { to } 1730 \\
1658 \text { to } 1704 \text { to } 1725 \\
1655 \text { to } 1718\end{array}$ & 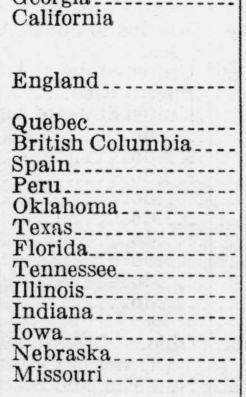 & 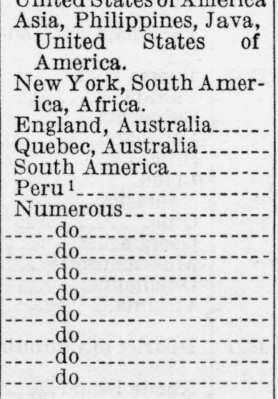 & $\begin{array}{l}\text { Solar eruption, } 1645 \text { to } \\
1703 \text {. Ter mag pulse, } \\
1645 \text { to } 1705 \text {. Earth- } \\
\text { current pulse, } 1645 \text { to } \\
1700 \text { Low-freq atm } \\
\text { increase, } 1650 \text { to } 1745 .\end{array}$ \\
\hline Apr. & $\begin{array}{l}1320 \text { to } 1400 \\
1320 \text { to } 1330 \text { to } 1430 \\
1325 \text { to } 1335 \text { to } 1345 \\
1340 \text { to } 1348\end{array}$ & $\begin{array}{l}\text { District of Columbia. } \\
\text { New York_... } \\
\text { Holland } \\
\text { England }\end{array}$ & $\begin{array}{l}\text { Ohio, Massachusetts... } \\
\text { Europee-. North and } \\
\text { Europe, } \\
\text { South America. } \\
\text { Numerous................ }\end{array}$ & $\left\{\begin{array}{l}\text { Solar eruption, from } \\
\text { before } 1330 \text { to } 1430 . \\
\text { Low-freq at m in: } \\
\text { crease, } 1310 \text { to } 1440 .\end{array}\right.$ \\
\hline Apr. 25 & 1427 to 1500 & District of Columbia & Ohio, Massachusetts.... & $\begin{array}{l}\text { Solar eruption, } 1428 \text { to } \\
1445 \text {. }\end{array}$ \\
\hline
\end{tabular}

${ }^{1}$ Disappearance or weakening of sky-waves reflected vertically from ionosphere. 
TABLE 1.-Data on radio fadeouts and other manifestations of sudden ionosphere disturbances-Continued

\begin{tabular}{|c|c|c|c|c|}
\hline Date & Time, GMT & Reported observed in & $\begin{array}{l}\text { Reported locations of } \\
\text { transmitting stations }\end{array}$ & $\begin{array}{l}\text { Reported solar and mag- } \\
\text { netic effects, etc. }\end{array}$ \\
\hline \multirow{2}{*}{$\begin{array}{c}1936 \\
\text { April } 25\end{array}$} & & & & \multirow{5}{*}{$\begin{array}{l}\text { Solar eruption, } 1650 \text { to } \\
1724 \text {. Ter mag pulse, } \\
1650 \text { to } 1700 \text {. Low-freq } \\
\text { atm increase, } 1658 \text { to } \\
1755 \text {. }\end{array}$} \\
\hline & 1653 to 1735 & District of Columbia. & $\begin{array}{l}\text { Ohio, Massachusetts, } \\
\text { District of Columbia. }{ }^{1}\end{array}$ & \\
\hline \multirow[t]{3}{*}{ Apr. 30} & 0940 to 1100 & Japan & Europe_............... & \\
\hline & $\begin{array}{l}1000 \text { to } 1100 \\
1000 \text { to } 1100\end{array}$ & & Japan & \\
\hline & 1000 to 1110 & England................ & - do do & \\
\hline May 8 & 2020 to 2029 to 2037 & District of Columbia. & Ohio, Massachusetts.... & \multirow{3}{*}{$\begin{array}{l}\text { Ter mag pulse, } 2020 \text { to } \\
2035 \text {. Earth-current } \\
\text { pulse, 2020. }\end{array}$} \\
\hline \multirow[t]{2}{*}{ May 14} & 1755 to 1759 & New York............... & Europe, United States & \\
\hline & 1750 to 1800 to 1817 & District of Columbia. & Ohio. & \\
\hline \multirow[t]{3}{*}{ May 15} & & Japan & Philippines, Asia, & \multirow{3}{*}{$\begin{array}{l}\text { Solar eruption, from be- } \\
\text { fore } 0704 \text { to } 0830 .\end{array}$} \\
\hline & 0550 to 0620 & Philippines_.......... & $\begin{array}{l}\text { Europe. } \\
\text { Japan }\end{array}$ & \\
\hline & 0600 to 0620 & France................... & - do do & \\
\hline \multirow[t]{5}{*}{ May 25} & 1233 to 1240 to 1256 & District of Columbia_ & $\begin{array}{l}\text { Ohio, Massachusetts, } \\
\text { District of Columbia.1 }\end{array}$ & \multirow{5}{*}{$\begin{array}{l}\text { Ter mag pulse, } 1233 \text { to } \\
1250 \text {. Earth-current } \\
\text { pulse, 1233 to } 1234 \text { to } \\
1236 \text {. Low-freq atm } \\
\text { increase, } 1228 \text { to } 1330 .\end{array}$} \\
\hline & $\begin{array}{l}1232 \text { to } 1243 \text { to } 1257 \\
1238\end{array}$ & New York...... & Numerous ................ & \\
\hline & 1235 to 1300 & Holland & $\begin{array}{l}\text { United states of America } \\
\text { Canada, Japan, Java....- }\end{array}$ & \\
\hline & 1232 to 1245 & France............ & $\begin{array}{l}\text { United States of A merica, } \\
\text { South America, Japan }\end{array}$ & \\
\hline & 1237 to 1245 & England .. & $\begin{array}{l}\text { Europe, South America, } \\
\text { Japan. }\end{array}$ & \\
\hline \multirow[t]{4}{*}{ May 26} & 1130 to 1135 & New York & Numerous................ & \multirow{11}{*}{$\begin{array}{l}\text { Solar eruption, } 1115 \text { to } \\
1203 \text {. Iow-freq atm } \\
\text { increase, } 1128 \text { to } 1158 .\end{array}$} \\
\hline & $\begin{array}{l}1130 \text { to } 1134 \\
1132 \text { to } 1139\end{array}$ & $\begin{array}{l}\text { District of Columbia } \\
\text { Holland. }\end{array}$ & $\begin{array}{l}\text { Ohio } \\
\text { Hungary }\end{array}$ & \\
\hline & 1131 & $\begin{array}{l}\text { France } \\
\text { England }\end{array}$ & Numerous & \\
\hline & & Hollond & Jenen Teme & \\
\hline May 27 & $\begin{array}{l}0335 \text { to } 0430 \\
0355 \text { to } 0410\end{array}$ & $\begin{array}{l}\text { Holland } \\
\text { California................. }\end{array}$ & $\begin{array}{l}\text { Japan, Java } \\
\text { Asia, Philippines, Java_- }\end{array}$ & \\
\hline & 0350 to 0415 & Japan & $\begin{array}{l}\text { California, Philippines, } \\
\text { Asia, Europe. }\end{array}$ & \\
\hline \multirow[t]{2}{*}{ May 27} & & & $\begin{array}{l}\text { North and South Amer- } \\
\text { ica. }\end{array}$ & \\
\hline & $\begin{array}{l}2345 \text { to } 2430 \\
2345 \text { to } 2430\end{array}$ & $\begin{array}{l}\text { Argentina... } \\
\text { California... }\end{array}$ & Japan & \\
\hline \multirow{3}{*}{ May 28} & 0345 to 0415 & & Asia, Philippines, Java_. & \\
\hline & 0340 to 0420 & Holland.... & Japan, Java & \\
\hline & 0330 to 0420 & Japan..... & $\begin{array}{l}\text { China, Philippines, Cal- } \\
\text { ifornia. }\end{array}$ & \\
\hline \multirow[t]{3}{*}{ May 28} & 0730 to 0745 & Philippines ..... & Hawaii & \multirow{3}{*}{$\begin{array}{l}\text { Solar eruption, } 0715 \text { to } \\
0800 \text {. Ter mag pulse, } \\
0725 \text { to } 0738 \text {. Low-freq } \\
\text { atm increase, } 0726 \text { to } \\
0800 .\end{array}$} \\
\hline & $\begin{array}{l}0728 \text { to } 0743 \\
0730 \text { to } 0800\end{array}$ & & $\begin{array}{l}\text { Asia, Philippines, Java.- } \\
\text { Japan, Austria, Java.-- }\end{array}$ & \\
\hline & $\begin{array}{l}0728 \text { to } 0730 \\
0720 \text { to } 0745\end{array}$ & $\begin{array}{l}\text { France. } \\
\text { Japan........... }\end{array}$ & $\begin{array}{l}\text { Numerous } \\
\text { Europe, Philippines..... }\end{array}$ & \\
\hline \multirow[t]{4}{*}{ May 28} & 1403 to 1416 to 1430 & District of Columbia. & Ohio, Massachusetts.... & \multirow{4}{*}{$\begin{array}{l}\text { Low-freq atm increase, } \\
1400 \text { to } 1450 .\end{array}$} \\
\hline & & & & \\
\hline & 1402 to 1430 & Holland. & $\begin{array}{l}\text { North and South Amer- } \\
\text { ica, Europe. }\end{array}$ & \\
\hline & 1405 & France................ & $\begin{array}{l}\text { lcd, Lurope. } \\
\text { Numerous................... }\end{array}$ & \\
\hline \multirow[t]{8}{*}{ May 28} & 1800 to 1808 to 1817 & District of Columbia_- & $\begin{array}{l}\text { Ohio, Massachusetts, } \\
\text { Texas, Nebraska, Ok- } \\
\text { lahoma. } \\
\text { Europe, North and } \\
\text { South America. }\end{array}$ & \multirow{8}{*}{$\begin{array}{l}\text { Ter mag pulse, } 1800 \text { to } \\
1850 \text {. Earth-current } \\
\text { pulse, } 1758 \text { to } 1807 . \\
\text { Low-freq atm increase } \\
1758 \text { to } 1907 .\end{array}$} \\
\hline & 1800 to 1823 & Oklahoma......... & Numerous . . . & \\
\hline & $\begin{array}{l}1800 \text { to } 1823 \\
1800 \text { to } 1823\end{array}$ & Texas & do do & \\
\hline & 1758 to 1815 & North Dakota............ & - & \\
\hline & 1800 to 1815 & Illinois & do & \\
\hline & $\begin{array}{l}1800 \text { to } 1815 \text { to } 1830 \\
1759 \text { to } 1820 \text { to } 1830\end{array}$ & British Columbia.... & do do & \\
\hline & 1800 to 1818 to 1828 & Arkansas..... & - & \\
\hline & $\begin{array}{l}1800 \text { to } 1818 \text { to } 1828 \\
1800 \text { to } 2000\end{array}$ & Kansas & $\mid \begin{array}{ll}-2 \\
-10\end{array}$ & \\
\hline
\end{tabular}

1 Disappearance or weakening of sky-waves reflected vertically from ionosphere. 
TABLE 1.-Data on radio fadeouts and other manifestations of sudden ionosphere disturbances-Continued

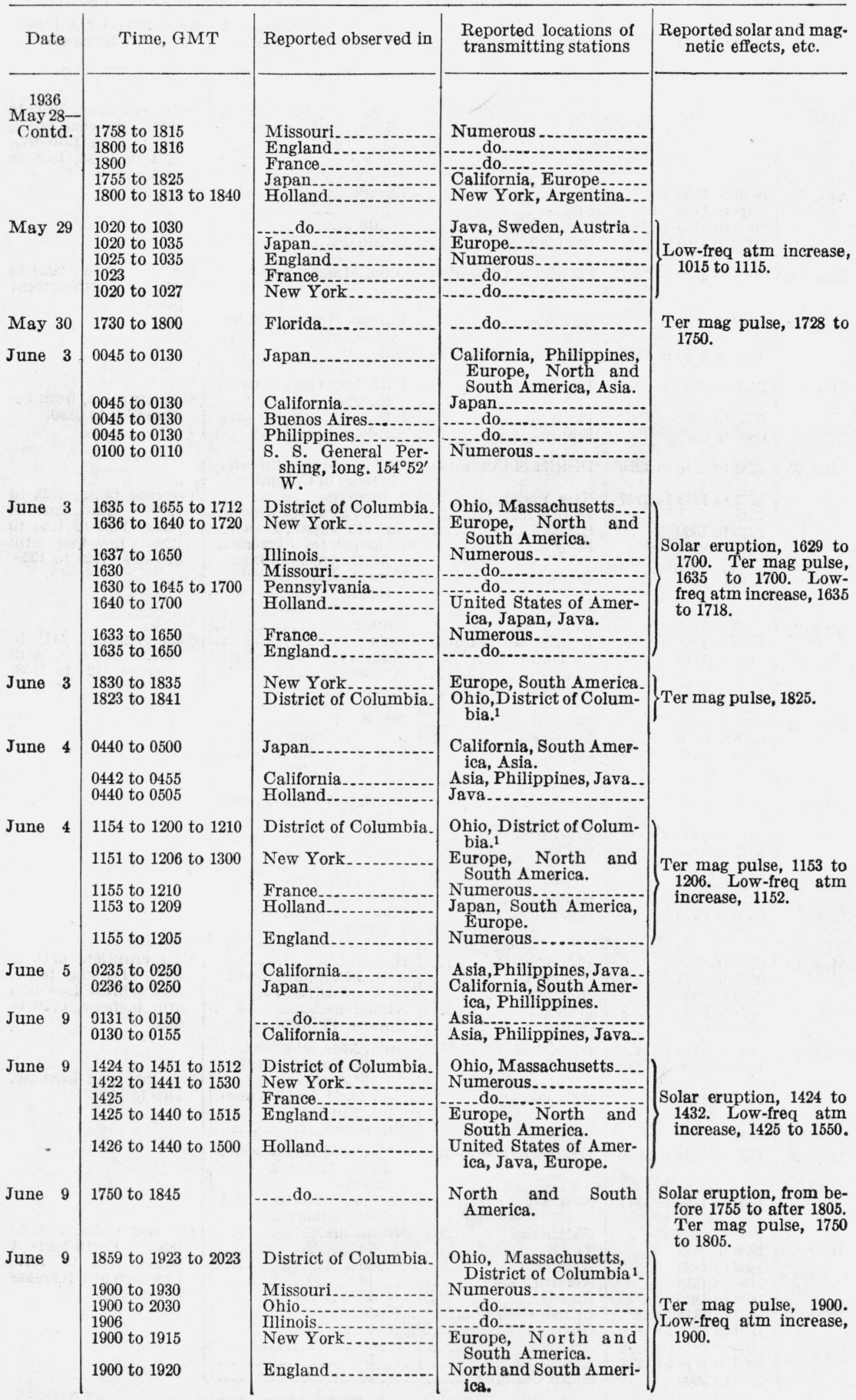

1 Disappearance or weakening of sky-waves reflected vertically from ionosphere. 
TABLE 1.-Data on radio fadeouts and other manifestations of sudden ionosphere disturbances-Continued

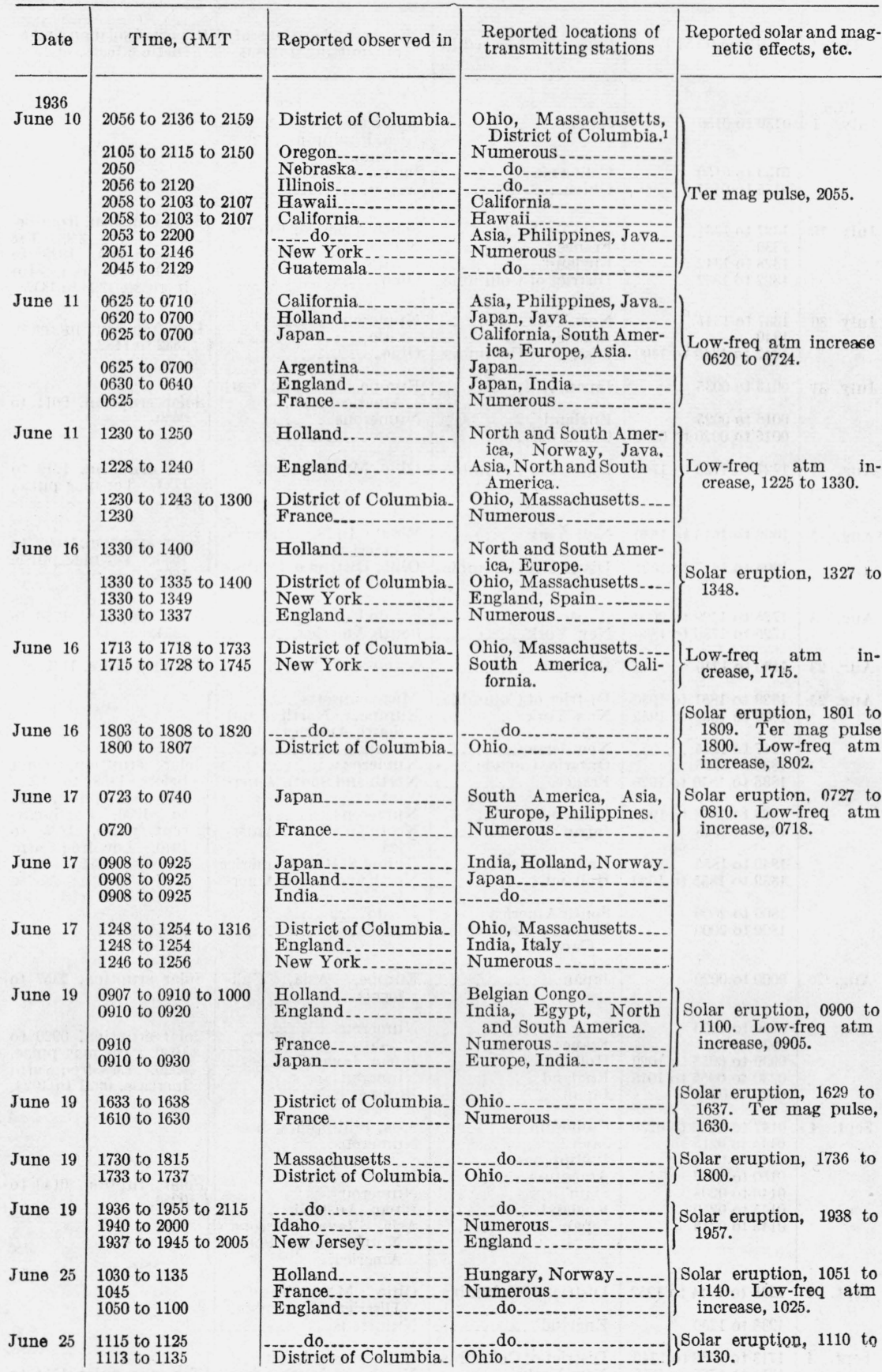

1 Disappearance or weakening of sky-waves reflected vertically from ionosphere. 
TABLE 1.-Data on radio fadeouts and other manifestations of sudden ionosphere disturbances-Continued

\begin{tabular}{|c|c|c|c|c|}
\hline Date & Time, GMT & Reported observed in & $\begin{array}{l}\text { Reported locations of } \\
\text { transmitting stations }\end{array}$ & $\begin{array}{l}\text { Reported solar and mag- } \\
\text { netic effects, etc. }\end{array}$ \\
\hline $\begin{array}{l}1936 \\
\text { July }\end{array}$ & $\begin{array}{l}0130 \text { to } 0150 \\
0133 \text { to } 0150 \\
0135 \text { to } 0155\end{array}$ & $\begin{array}{l}\text { Japan } \\
\text { California................. }\end{array}$ & $\begin{array}{l}\text { North and South Amer- } \\
\text { ica, Philippines, Java, } \\
\text { China. } \\
\text { Japan }\end{array}$ & \\
\hline July 15 & $\begin{array}{l}1327 \text { to } 1331 \ldots \ldots . . . . \\
1330 \\
1328 \text { to } 1342 \\
1322 \text { to } 1332\end{array}$ & $\begin{array}{l}\text { New York } \\
\text { France } \\
\text { England. } \\
\text { District of Columbia- }\end{array}$ & $\begin{array}{l}\text { South America, Europe- } \\
\text { Numerous_. }\end{array}$ & $\left\{\begin{array}{l}\text { Solar eruption, from be- } \\
\text { fore } 1330 \text { to } 1340 \text {. Ter } \\
\text { mag pulse, 1325 to } \\
1330 \text {. Low-freq atm } \\
\text { increase, } 1328 \text { to } 1415 .\end{array}\right.$ \\
\hline July 30 & $\begin{array}{l}1337 \text { to } 1347 \\
1340 \\
1342 \text { to } 1346 \text { to } 1400\end{array}$ & $\begin{array}{l}\text { New York } \\
\text { France } \\
\text { District of Columbia }\end{array}$ & $\begin{array}{l}\text { Numerous_ } \\
\text { Ohio }\end{array}$ & $\left\{\begin{array}{l}\text { Low-freq atm increase, } \\
1332 \text { to } 1432 .\end{array}\right.$ \\
\hline July 31 & $\begin{array}{l}0015 \text { to } 0035 \\
0016 \text { to } 0025 \\
0015 \text { to } 0020 \text { to } 0030\end{array}$ & $\begin{array}{l}\text { Japan } \\
\text { England............. } \\
\text { California... }\end{array}$ & $\begin{array}{l}\text { Europe, North and South } \\
\text { America, Asia. } \\
\text { Numerous. }\end{array}$ & $\left\{\begin{array}{l}\text { Solar eruption, } 0011 \text { to } \\
0030 \text {. }\end{array}\right.$ \\
\hline Aug. 4 & 1727 to 1733 to 1746 & District of Columbia & Ohio, Massachusetts .... & $\begin{array}{l}\text { Solar eruption, } 1719 \text { to } \\
1723 \text {. Ter mag pulse, } \\
1725 \text {. }\end{array}$ \\
\hline Aug. 5 & $\begin{array}{l}1609 \text { to } 1615 \text { to } 1630 \\
1606 \text { to } 1617 \text { to } 1621\end{array}$ & District of Columbia. & $\begin{array}{l}\text { West Indies, South } \\
\text { America, Europe. } \\
\text { Ohio, District of Colum- } \\
\text { bia. } 1\end{array}$ & $\begin{array}{l}\text { Solar eruption, } 1603 \text { to } \\
1630 \text {. Ter mag pulse, } \\
1605 .\end{array}$ \\
\hline Aug. 8 & & New York & South America........... & $\left\{\begin{array}{l}\text { Solar eruption, } 1716 \text { to } \\
1834 .\end{array}\right.$ \\
\hline Aug. 23 & 1130 to 1210 & England.... & Numerous............ & Ter mag pulse, 1149. \\
\hline Aug. 25 & $\begin{array}{l}1829 \text { to } 1851 \text { to } 1930 \\
1830 \text { to } 1850 \text { to } 1955 \\
1917 \text { to } 1945 \\
1830 \text { to } 1905 \\
1835 \text { to } 1850 \text { to } 1920 \\
1828 \text { to } 1854 \text { to } 1925 \\
1835 \text { to } 1908 \\
1840 \text { to } 1855 \\
1839 \text { to } 1855 \text { to } 1920 \\
1800 \text { to } 2000 \\
1800 \text { to } 2000\end{array}$ & 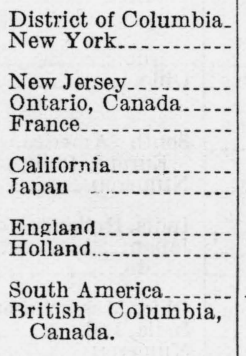 & $\begin{array}{l}\text { Massachusetts } \\
\text { Europe, North and } \\
\text { South America. } \\
\text { Bermuda. } \\
\text { Numerous. } \\
\text { North and South Amer- } \\
\text { ica. } \\
\text { Numerous } \\
\text { North and South Amer- } \\
\text { ica. } \\
\text { United States of America } \\
\text { North and South Amer- } \\
\text { ica. } \\
\text { Canada. }\end{array}$ & $\begin{array}{l}\text { Solar eruption, from } \\
\text { before } 1858 \text { to } 1922 . \\
\text { Ter mag pulse, 1825 } \\
\text { to 1930. Earth-cur- } \\
\text { rent pulse, } 1825 \text { to } \\
\text { 1910. Low-freq atm } \\
\text { increase, 1831. }\end{array}$ \\
\hline Aug. 26 & 0000 to 0020 & Japan...... & $\begin{array}{l}\text { Europe, Asia, Cali- } \\
\text { fornia. }\end{array}$ & $\begin{array}{l}\text { Solar eruption, } 2357 \text { to } \\
0001 \text {. }\end{array}$ \\
\hline Aug. 28 & $\begin{array}{l}0930 \text { to } 1020 \\
0930 \\
0930 \text { to } 0955 \text { to } 1020 \\
0930 \text { to } 0955 \text { to } 1015 \\
0929 \text { to } 0945\end{array}$ & $\begin{array}{l}\text { Italy } \\
\text { France. } \\
\text { Holland } \\
\text { England-- } \\
\text { Japan }\end{array}$ & $\begin{array}{l}\text { Numerous } \\
\text { Japan, Java } \\
\text { Numerous } \\
\text { Europe. }\end{array}$ & $\left\{\begin{array}{l}\text { Solar eruption, } 0920 \text { to } \\
1030 \text {. Ter mag pulse, } \\
0920 \text {. Low-freq atm } \\
\text { increase, } 0923 \text { to } 1023 .\end{array}\right.$ \\
\hline Sept. 4 & $\begin{array}{l}0147 \text { to } 0202 \text { to } 0230 \\
0145 \text { to } 0215 \\
0145 \text { to } 0200 \\
0150 \text { to } 0200 \\
0146 \text { to } 0208 \\
0145 \text { to } 0210 \\
0145 \text { to } 0215\end{array}$ & $\begin{array}{l}\text { California } \\
\text { Java } \\
\text { Philippines. } \\
\text { Argentina } \\
\text { Siam } \\
\text { England. } \\
\text { Japan }\end{array}$ & $\begin{array}{l}\text { Asia, Philippines, Java_. } \\
\text { Numerous_. do } \\
\text { Japan } \\
\text { Numerous_-_ } \\
\text { Japan, Australia.-.... } \\
\text { Asia, Java, Europe, } \\
\text { North and South } \\
\text { America. }\end{array}$ & $\begin{array}{l}\text { Solar eruption, } 0140 \text { to } \\
0256 \text {. }\end{array}$ \\
\hline Sept. 4 & $\begin{array}{l}1238 \text { to } 1244 \text { to } 1252 \\
1238 \text { to } 1250\end{array}$ & $\begin{array}{l}\text { District of Columbia. } \\
\text { England }\end{array}$ & $\begin{array}{c}\text { Ohjo, Massachusetts, } \\
\text { District of Columbia. } \\
\text { Numerous.............. }\end{array}$ & \\
\hline Sept. 4 & $\begin{array}{l}1713 \text { to } 1732 \text { to } 1740 \\
1715 \text { to } 1720 \text { to } 1750 \\
1714 \text { to } 1723 \text { to } 1740\end{array}$ & $\begin{array}{l}\text { District of Columbia. } \\
\text { New York } \\
\text { California................. }\end{array}$ & $\begin{array}{l}\text { Ohio, Massachusetts.... } \\
\text { North and South Amer- } \\
\text { ica. } \\
\text { United States of Amer- } \\
\text { ica. }\end{array}$ & $\begin{array}{l}\text { Ter mag pulse, } 1714 \text { to } \\
1721 . \text { Earth-current } \\
\text { pulse, 1714. }\end{array}$ \\
\hline
\end{tabular}

1 Disappearance or weakening of sky-waves reflected vertically from ionosphere. 
TABLE 1.-Data on radio fadeouts and other manifestations of sudden ionosphere disturbances-Continued

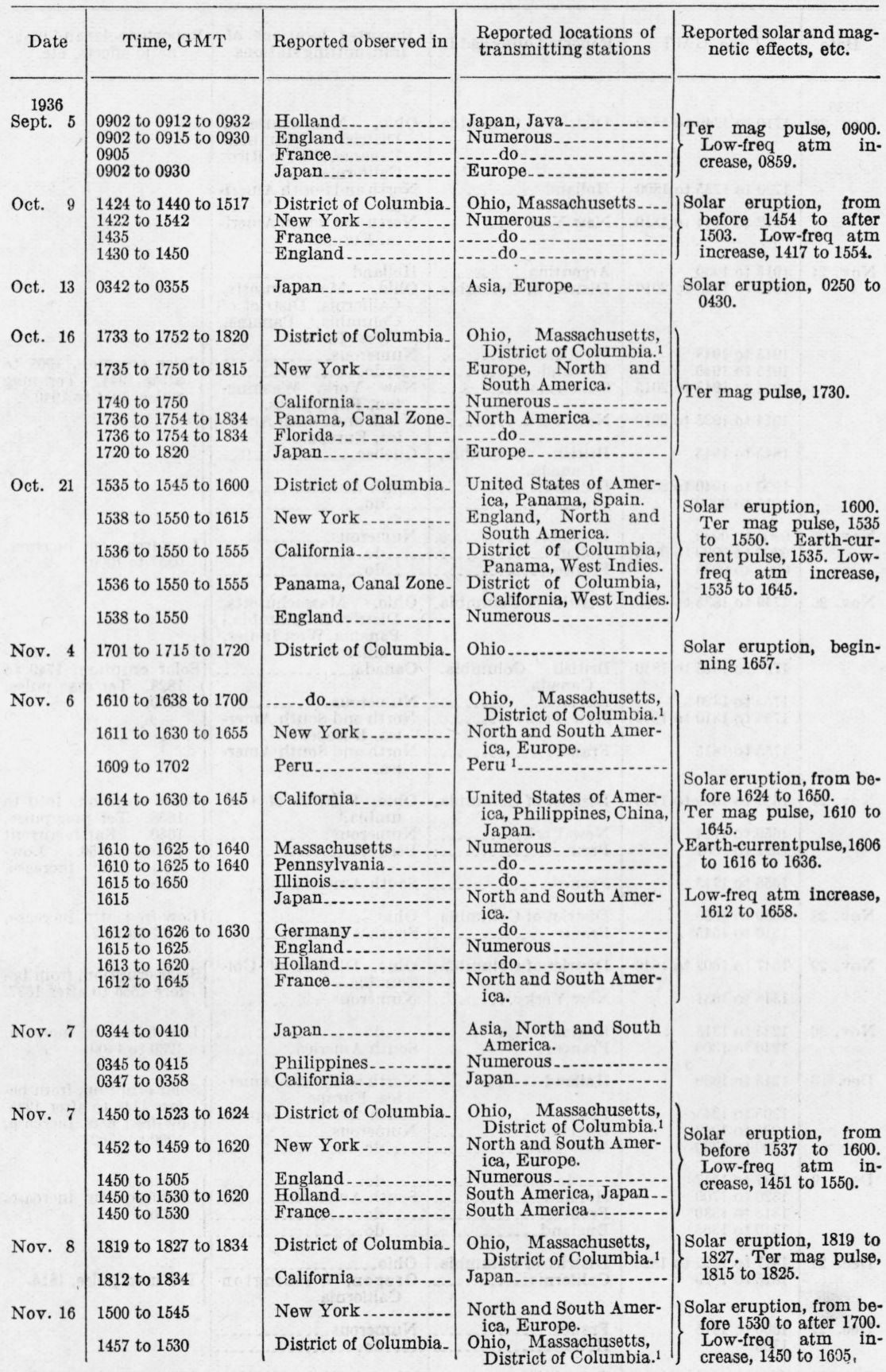

1 Disappearance or weakening of sky-waves reflected vertically from ionosphere. 
TABLE 1.-Data on radio fadeouts and other manifestations of sudden ionosphere disturbances-Continued

\begin{tabular}{|c|c|c|c|c|}
\hline Date & Time, GMT & Reported observed in & $\begin{array}{l}\text { Reported locations of } \\
\text { transmitting stations }\end{array}$ & $\begin{array}{l}\text { Reported solar and mag- } \\
\text { netic effects, etc. }\end{array}$ \\
\hline $\begin{array}{l}1936 \\
\text { Nov. } 24\end{array}$ & $\begin{array}{l}1720 \text { to } 1735 \text { to } 1800 \\
1712 \text { to } 1744 \text { to } 1810\end{array}$ & $\begin{array}{l}\text { Holland...- } \\
\text { New York. }\end{array}$ & $\begin{array}{l}\text { Ohio, Massachusetts, } \\
\text { District of Columbia, } \\
\text { Panama, Puerto Rico, } \\
\text { California. } \\
\text { North and South Ameri- } \\
\text { ca. } \\
\text { North and South Ameri- } \\
\text { ca, Europe. }\end{array}$ & \\
\hline Nov. 24 & $\begin{array}{l}1915 \text { to } 1948 \\
1915 \text { to } 1940 \\
1914 \text { to } 1945 \text { to } 2015 \\
1914 \text { to } 1935 \text { to } 2010 \\
1845 \text { to } 1945 \\
1920 \text { to } 1940 \text { to } 2000 \\
1915 \text { to } 2000\end{array}$ & 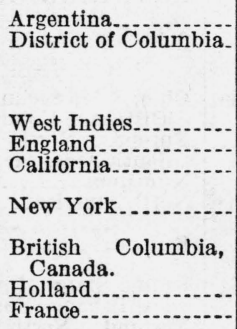 & 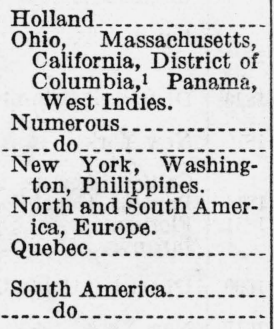 & $\begin{array}{l}\text { Solar eruption, } 1908 \text { to } \\
\text { after } 1944 \text {. Ter mag } \\
\text { pulse, } 1914 \text { to } 1940 .\end{array}$ \\
\hline Nov. 26 & $\begin{array}{l}0900 \text { to } 0930 \text { - } \\
0900 \text { to } 0920 \text { to } 0940 \\
0901 \text { to } 0925\end{array}$ & $\begin{array}{l}\text { England } \\
\text { Holland } \\
\text { France.... }\end{array}$ & Numerous. & $\begin{array}{l}\text { Low-freq atm increase, } \\
0857 \text { to } 1000 \text {. }\end{array}$ \\
\hline Nor. 26 & $\begin{array}{l}1750 \text { to } 1825 \text { to } 1840 \\
1755 \text { to } 1820 \\
1753 \text { to } 1810 \text { to } 1900 \\
1755 \text { to } 1815\end{array}$ & 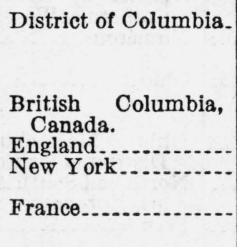 & $\begin{array}{l}\text { Ohio, Massachusetts, } \\
\text { District of Columbia, } \\
\text { Panama, West Indies, } \\
\text { California. } \\
\text { Canada...... } \\
\text { Numerous } \\
\text { North and South Amer- } \\
\text { ica, Europe. } \\
\text { North and South Amer- } \\
\text { ica. }\end{array}$ & $\begin{array}{l}\text { Solar eruption, } 1749 \text { to } \\
1828 \text {. Ter mag pulse, } \\
\text { 1750. }\end{array}$ \\
\hline Nov. 27 & $\begin{array}{l}1651 \text { to } 1659 \text { to } 1713 \\
1650 \text { to } 1724 \\
1651 \text { to } 1654 \\
1656 \text { to } 1715\end{array}$ & $\begin{array}{l}\text { District of Columbia } \\
\text { New York } \\
\text { Peru } \\
\text { France }\end{array}$ & $\begin{array}{l}\text { Ohio, District of Col- } \\
\text { umbia.1 } \\
\text { Numerous } \\
\text { Peru }{ }^{1} . \\
\text { South America........... }\end{array}$ & $\left\{\begin{array}{l}\text { Solar eruption, } 1650 \text { to } \\
1658 \text {. Ter mag pulse, } \\
1650 \text {. Earth-current } \\
\text { pulse, } 1650 \text { Low- } \\
\text { freq atm increase, } \\
1658 \text {. }\end{array}\right.$ \\
\hline Nov. 28 & & $\begin{array}{l}\text { District of Columbia } \\
\text { France }\end{array}$ & $\begin{array}{l}\text { Ohio } \\
\text { South America }\end{array}$ & $\left\{\begin{array}{l}\text { Low-freq atm increase, } \\
1507 \text { to } 1537 .\end{array}\right.$ \\
\hline Nov. 29 & $\begin{array}{l}1547 \text { to } 1602 \text { to } 1640 \\
1546 \text { to } 1631\end{array}$ & $\begin{array}{l}\text { District of Columbia } \\
\text { New York }\end{array}$ & $\begin{array}{l}\text { Ohio, District of Col- } \\
\text { umbia.1 } \\
\text { Numerous }\end{array}$ & $\begin{array}{l}\text { Solar eruption, from be- } \\
\text { fore } 1555 \text { to after } 1637 .\end{array}$ \\
\hline Nov. 30 & $\begin{array}{l}1235 \text { to } 1315 \\
1240 \text { to } 1300\end{array}$ & & South America...... do & $\left\{\begin{array}{l}\text { Low-freq atm increase, } \\
1230 \text { to } 1400 \text {. }\end{array}\right.$ \\
\hline Dec. 3 & $\begin{array}{l}1215 \text { to } 1330 \\
1205 \text { to } 1245 \\
1205 \text { to } 1242 \\
1200 \text { to } 1320\end{array}$ & $\begin{array}{l}\text { Holland } \\
\text { France } \\
\text { England } \\
\text { New York }\end{array}$ & $\begin{array}{l}\text { North and South Amer- } \\
\text { ica, Europe. } \\
\text { South America, Japan.. } \\
\text { Numerous }\end{array}$ & $\begin{array}{l}\text { Solar eruption, from be- } \\
\text { fore } 114 \mathrm{E} \text { to after } 1245 . \\
\text { Low-freq atm increase, } \\
1200 \text { to } 1302 \text {. }\end{array}$ \\
\hline Dec. 9 & $\begin{array}{l}1337 \text { to } 1517 \\
1320 \text { to } 1700 \\
1315 \text { to } 1330 \\
1310 \text { to } 1355\end{array}$ & $\begin{array}{l}\text { Holland } \\
\text { France } \\
\text { England....... }\end{array}$ & $\begin{array}{l}\text { South America. } \\
\text { do }\end{array}$ & $\begin{array}{l}\text { Low-freq atm increase, } \\
1300 .\end{array}$ \\
\hline Dec. 21 & $\begin{array}{l}1817 \text { to } 1822 \text { to } 1828 \\
1825 \text { to } 1829\end{array}$ & $\begin{array}{l}\text { District of Columbia. } \\
\text { Californis.............. }\end{array}$ & $\begin{array}{l}\text { Ohio... } \\
\text { Oregon, Washington } \\
\text { California. }\end{array}$ & Ter mag pulse, 1815 . \\
\hline Dec. 22 & $\begin{array}{l}1305 \text { to } 1315 \\
1303\end{array}$ & $\begin{array}{l}\text { France } \\
\text { Holland...... }\end{array}$ & Numerous. & \\
\hline Dec. 24 & 2202 to 2220 & California.............. & $\begin{array}{l}\text { Western United States } \\
\text { of America, Japan, } \\
\text { China, Philippines. }\end{array}$ & $\begin{array}{l}\text { Solar eruption, } 2200 \text { to } \\
2218 \text {. }\end{array}$ \\
\hline
\end{tabular}

1 Disappearance or weakening of sky-waves reflected vertically from ionosphere. 
TABLE 1.-Data on radio fadeouts and other manifestations of sudden ionosphere disturbances-Continued

\begin{tabular}{|c|c|c|c|c|}
\hline Date & Time, GMT & Reported observed in & $\begin{array}{l}\text { Reported locations of } \\
\text { transmitting stations }\end{array}$ & $\begin{array}{l}\text { Reported solar and mag- } \\
\text { netic effects, etc. }\end{array}$ \\
\hline $\begin{array}{l}1936 \\
\text { Dec. } 24\end{array}$ & 2348 to 2400 & California_. & $\begin{array}{l}\text { Western United States } \\
\text { of America, Japan, } \\
\text { China, Philippines. }\end{array}$ & $\begin{array}{l}\text { Solar eruption, } 2349 \text { to } \\
2358 \text {. Ter mag pulse, } \\
2348 \text {. }\end{array}$ \\
\hline Dec. 26 & $\begin{array}{l}1932 \text { to } 1958 \text { to } 2019 \\
1944 \text { to } 1954 \text { to } 2015 \\
1939 \text { to } 2016\end{array}$ & $\begin{array}{l}\text { District of Columbia } \\
\text { New York } \\
\text { California }\end{array}$ & $\begin{array}{l}\text { Ohio, Massachusetts... } \\
\text { Numerous } \\
\text { United States of Ameri- } \\
\text { ca, Japan, China, } \\
\text { Philippines. }\end{array}$ & \\
\hline Dec. 28 & $\begin{array}{l}1055 \text { to } 1100 \\
1100 \\
1100 \text { to } 1110\end{array}$ & $\begin{array}{l}\text { England } \\
\text { Holland. } \\
\text { France }\end{array}$ & Numerous & $\left\{\begin{array}{l}\text { Low-freq atm increase, } \\
1103 \text { to } 1145 .\end{array}\right.$ \\
\hline Dec. 29 & $\begin{array}{l}0820 \text { to } 0835 \\
0820 \\
0848 \text { to } 0910\end{array}$ & $\begin{array}{l}\text { Holland.-. } \\
\text { England........ }\end{array}$ & $\begin{array}{l}\text { Africa, Asia } \\
\text { Java_, } \\
\text { Numerous. }\end{array}$ & \\
\hline Dec. 30 & 0852 to 0908 & France.... & Africa, Asia.. & $\begin{array}{l}\text { Low-freq atm increase, } \\
0848 \text { to } 0920 \text {. }\end{array}$ \\
\hline Dec. 30 & 1031 to 1045 & England.... & Numerous... & $\begin{array}{l}\text { Solar eruption, from be- } \\
\text { fore } 0944 \text { to } 1056 \text {. } \\
\text { Low freq atm increase, } \\
1030 .\end{array}$ \\
\hline Dec. 30 & 1100 to 1120 & .... do .. & do & $\begin{array}{l}\text { Solar eruption, from be- } \\
\text { fore } 1053 \text { to } 1217 \text {. } \\
\text { Low-freq atm increase, } \\
1053 \text {. }\end{array}$ \\
\hline
\end{tabular}

Table 1 summarizes the data from all sources. It is regretted that only a summary can be given; the complete details are so voluminous that it is not practicable to tell the whole story of each of the occurrences. The complete details would occupy hundreds of pages. Thus, in the case of numerous publications listed in section VII, the entire article is devoted to observations at a single place of a single one of these occurrences. Table 1 includes some information based on published articles. Most of the data, however, were derived from observations made at the National Bureau of Standards and from reports sent by other observers to the author. Acknowledgements of this assistance are given at the end of this paper.

Even though they represent very extensive observations, the data we have do not give comprehensive information on the occurrences. In some cases we have knowledge of the disturbance from only two places of observation (and effects reported from only one place are included in two or three cases, where radio waves were received over numerous paths and the effects were extremely intense and clearly authentic). It would be desirable that we have for each occurrence information from numerous points all over the world, on the effects which occurred in radio transmission, terrestrial magnetism, and earth currents. In no case have we such complete information, and in many cases we also lack certainty as to whether a solar eruption occurred at the time. The incomplete character of our knowledge should be remembered in interpreting the data.

This investigation has dealt primarily with the radio aspects of the sudden ionosphere disturbances, as the form of table 1 indicates. The table gives, for each receiving location reporting a radio fadeout, the average time of the fadeout of high-frequency radio waves for 
each of the locations of transmitting stations whose emissions were affected. For the terrestrial magnetic and earth-current pulses, the effects upon atmospherics, and solar eruptions, only the times of occurrence are given. All times given in this paper are in GMT,i. e., Greenwich Mean Time. Eastern Standard Time is 5 hours less than GMT.

In the second column of table 1, the first time given on each line is the time of beginning of the radio fadeout. Where three times are given, the second is the time when the radio signals began to come in again and the third is the time when the intensities had risen to normal. Where two times are given, the second is in most cases the time when the radio signals had risen to approximately normal.

On account of the necessity of compressing the data into a table of reasonable length, the times given are in most cases averages. The individual times of beginning of the radio fadeout or other effect agree, however, in almost all cases within 2 or 3 minutes. For the radio fadeouts, the times of ending differed greatly. The times given are averages. (See section III regarding the differences at different frequencies.)

The data on the radio fadeouts are based on: (a) Experiences of operators receiving radio signals; (b) graphical records from fieldintensity recorders; and (c) observations of echo signal pulses from the ionosphere. All the radio fadeouts which occurred at Washington, including practically all observable in the American hemisphere, after August 1935, were recorded on automatic field-intensity recorders maintained by the National Bureau of Standards at Meadows, Md., near Washington, D. C. These recorders made continuous records of the field intensities of certain high-frequency transmitting stations.

Typical fadeouts as recorded graphically are shown in figures 1 to 8. Note the sudden drop of intensity and the subsequent gradual rise. As observed by a radio operator, a radio fadeout is simply the sudden disappearance of the signal from a distant high-frequency transmitting station. In most instances the intensity of the received signal was reduced to zero, but in some it merely sank to an intensity so low as to be unreadable. Whenever echo signal pulses were being transmitted at the time of the fadeout in a given locality, the ionosphere echoes weakened or disappeared. This is also illustrated in the figures 1 to 8 . The instances of these phenomena given in these eight figures are illustrative of many thousands of observations for which the author has data on file.

In the last column of table 1 are numerous entries of increase of radio atmospherics at the same times as the other effects. These are all based on data published by R. Bureau, of France. They refer to an increase in atmospherics as recorded on frequencies between 27 and $40 \mathrm{kc} / \mathrm{s}$, at observing points in France and Northern Africa.

The expression "Ter. mag. pulse", in the last column of table 1, means an abrupt change in one or more of the terrestrial magnetic elements, viz horizontal intensity, vertical intensity, and declination, usually in all three. Some typical examples are shown in figures 1 to 8. Most of the data on terrestrial magnetic effects were obtained from the magnetograms of the Cheltenham, Md., Observatory of the U. S. Coast and Geodetic Survey, supplemented in some cases by information from other magnetic observatories, particularly the Mt. Wilson, Calif., Observatory of the Carnegie Institution of Washington. A 

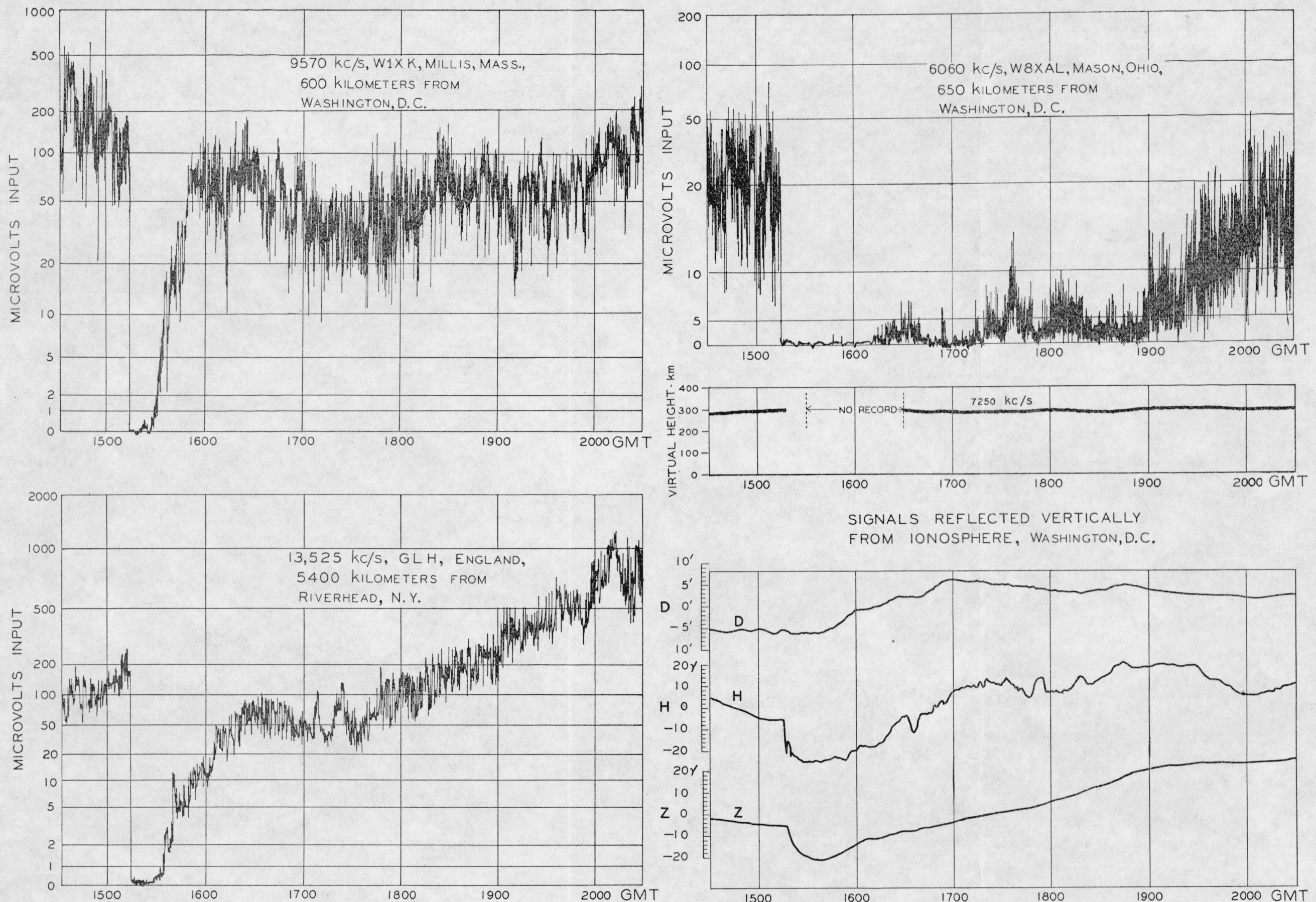

SIGNALS REFLECTED VERTICALLY FROM IONOSPHERE, WASHINGTON,D.C.

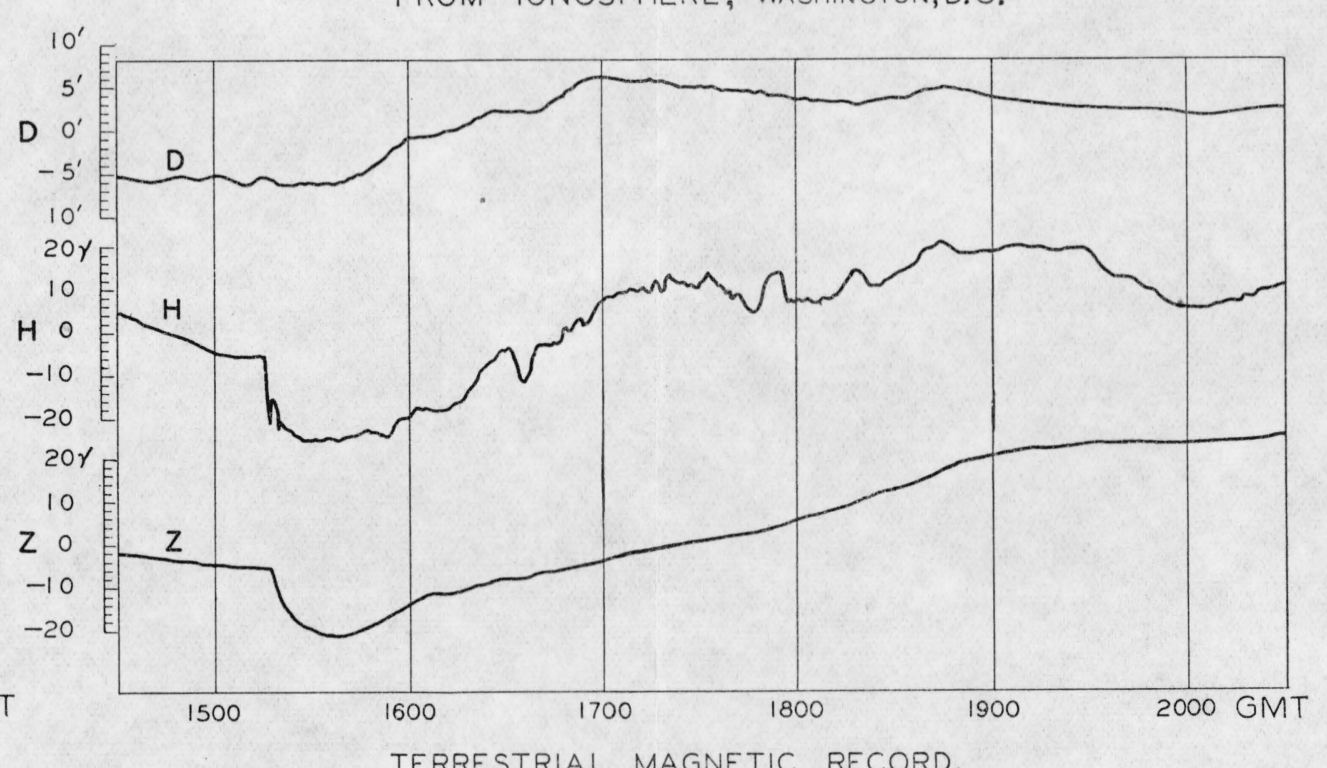

TERRESTRIAL MAGNETIC RECORD, 

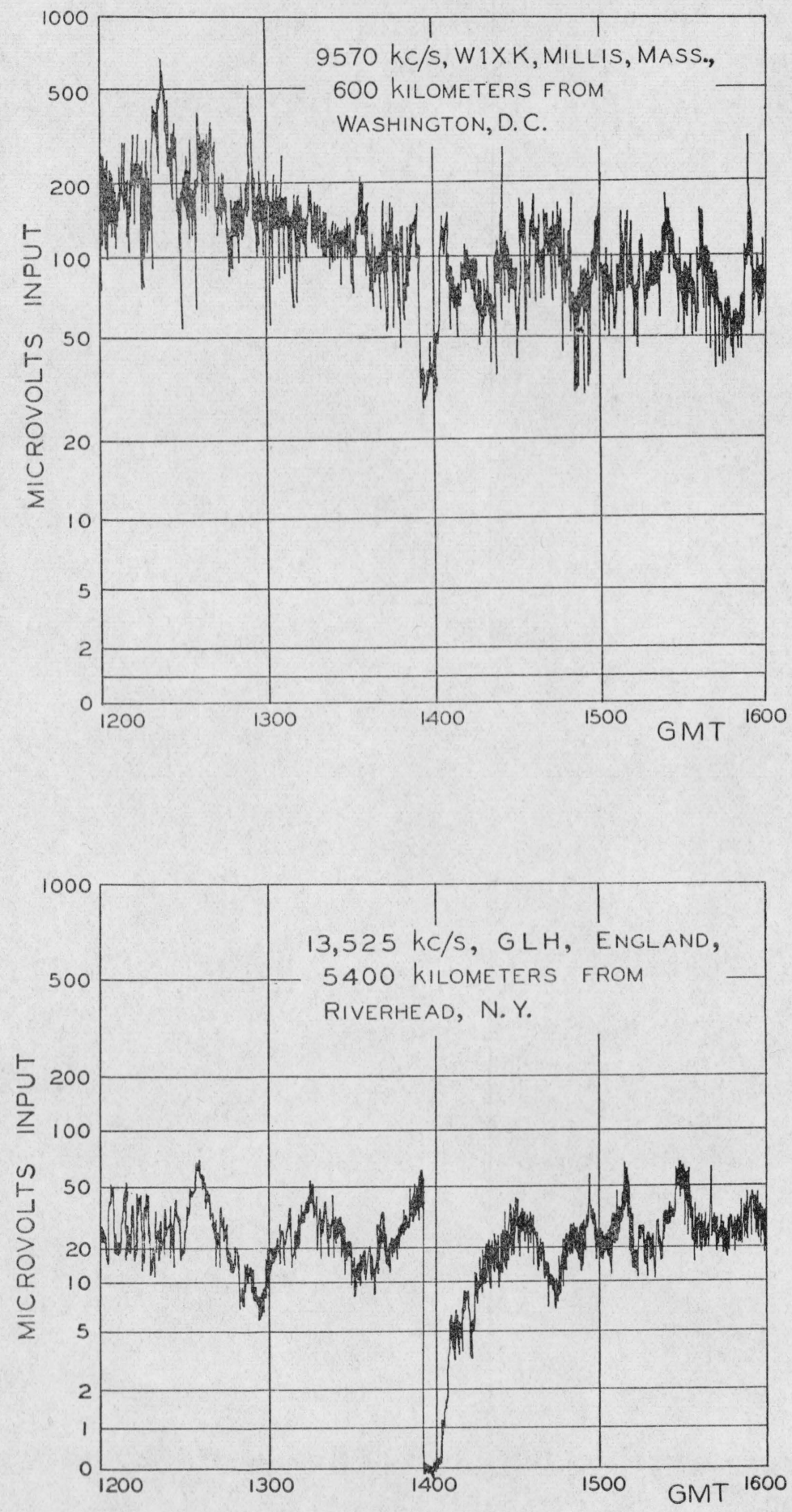
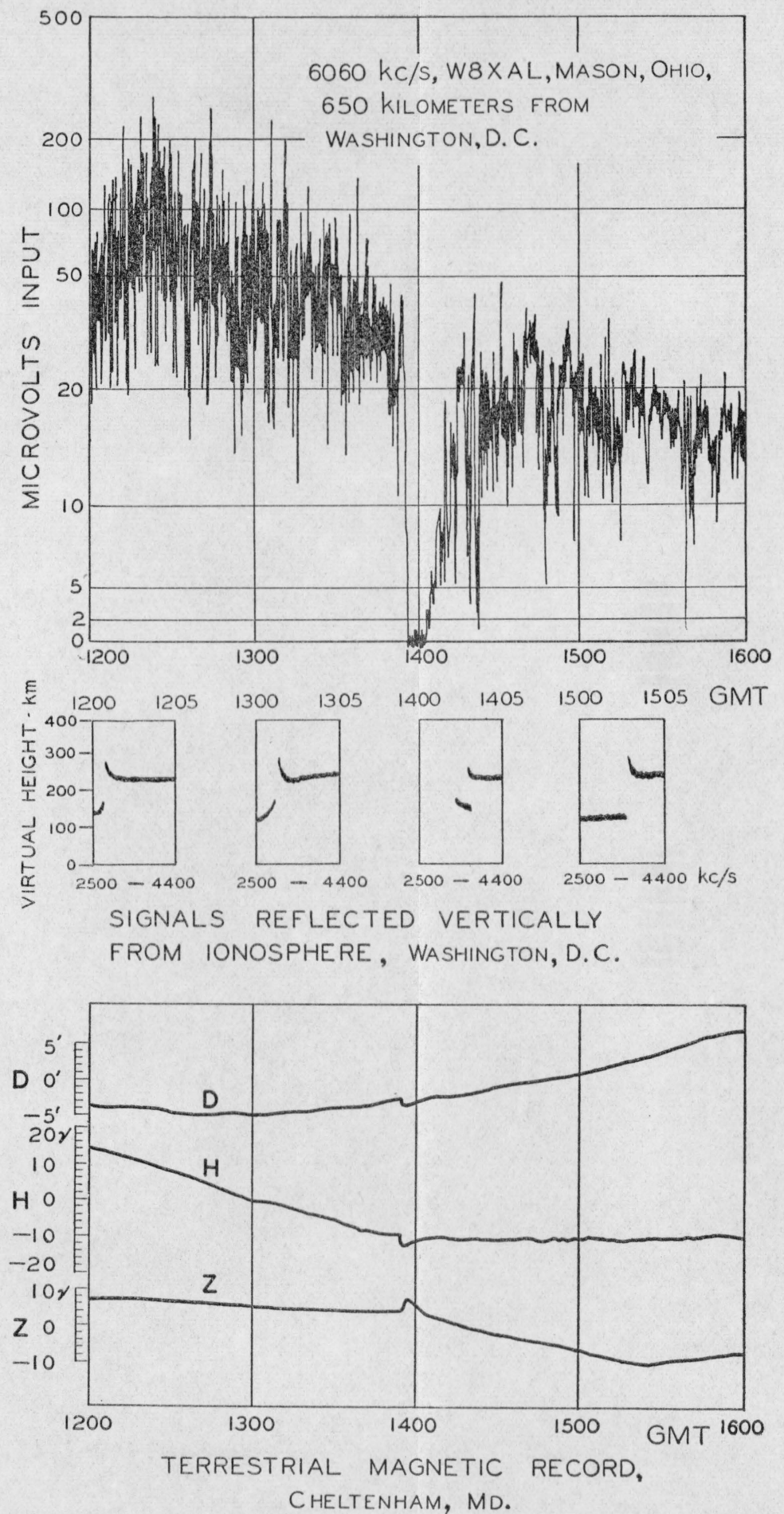

ChELTENHAM, MD.

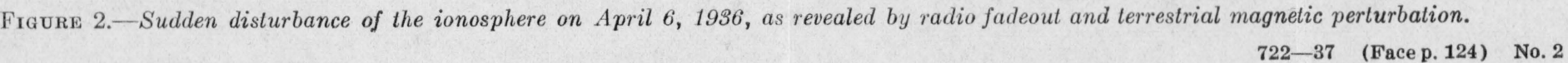



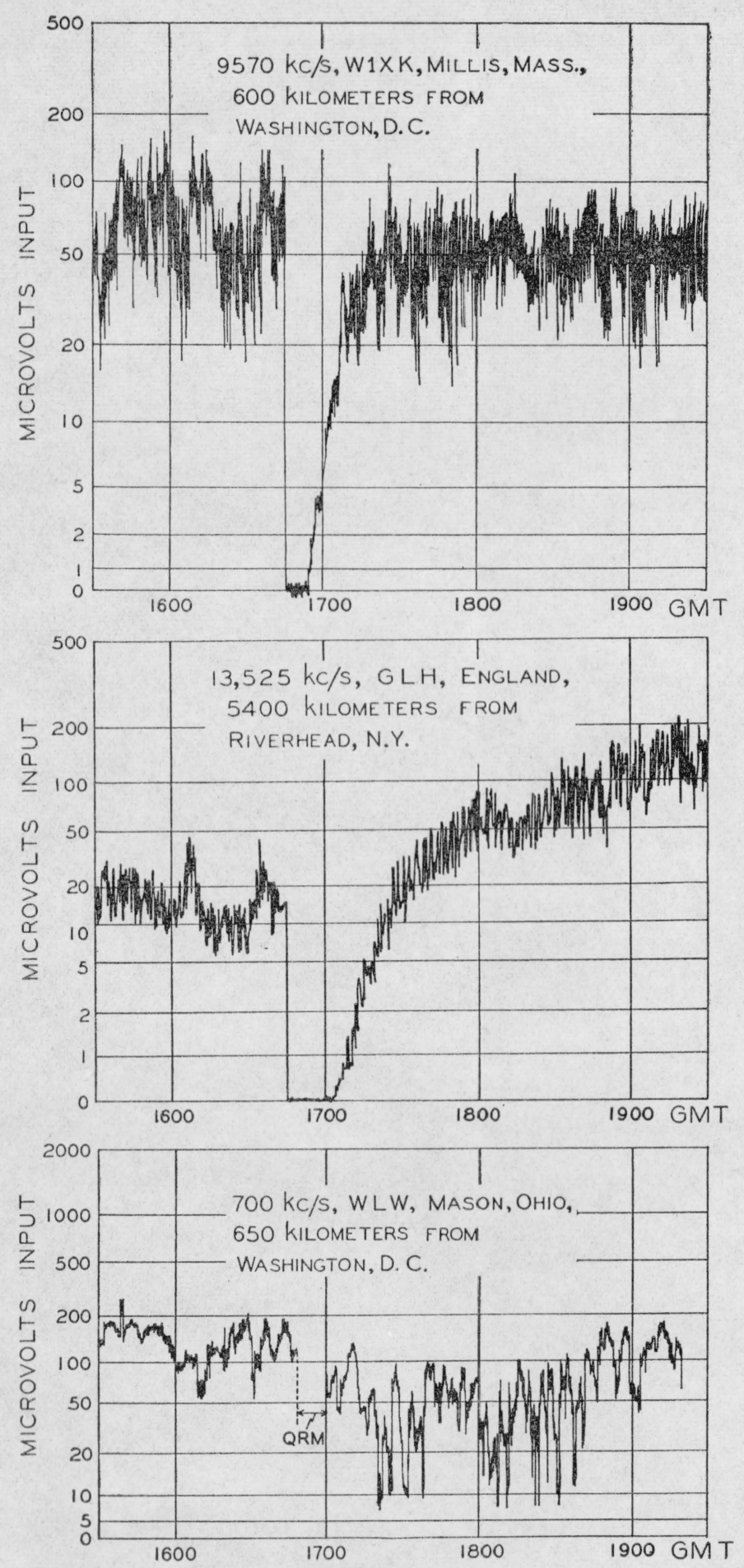

FigURE 3.-Sudden disturbance of the ionosphere on April 8, 1936, as revealed by radio fadeout and terrestrial magnetic perlurbation.
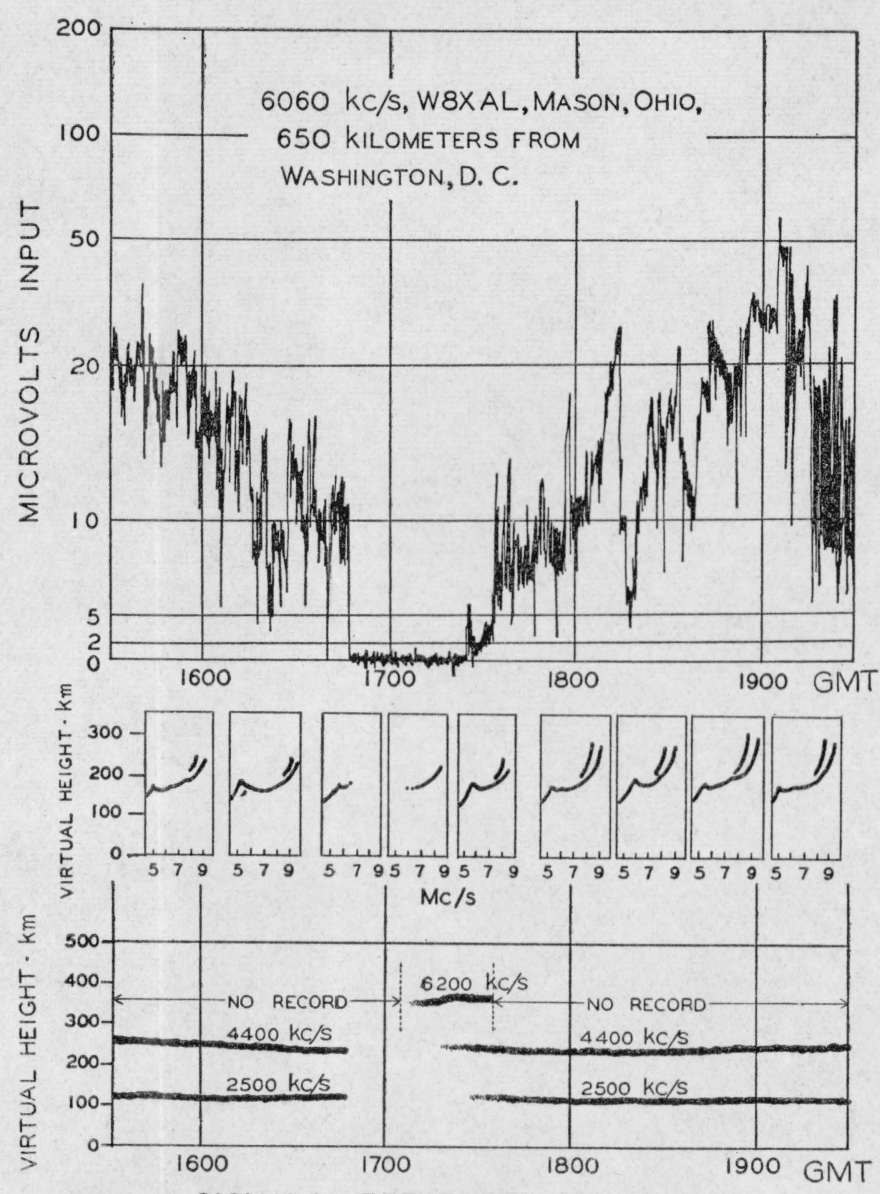

SIGNALS REFLECTED VERTICALLY

FROM IONOSPHERE, WASHINGTON, D.C.

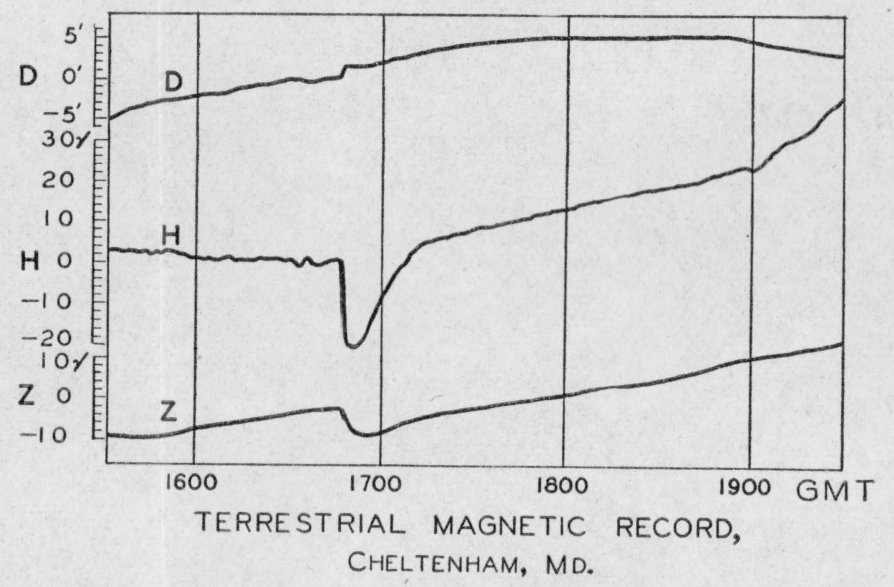

722-37 (Face p. 124) No. 3 

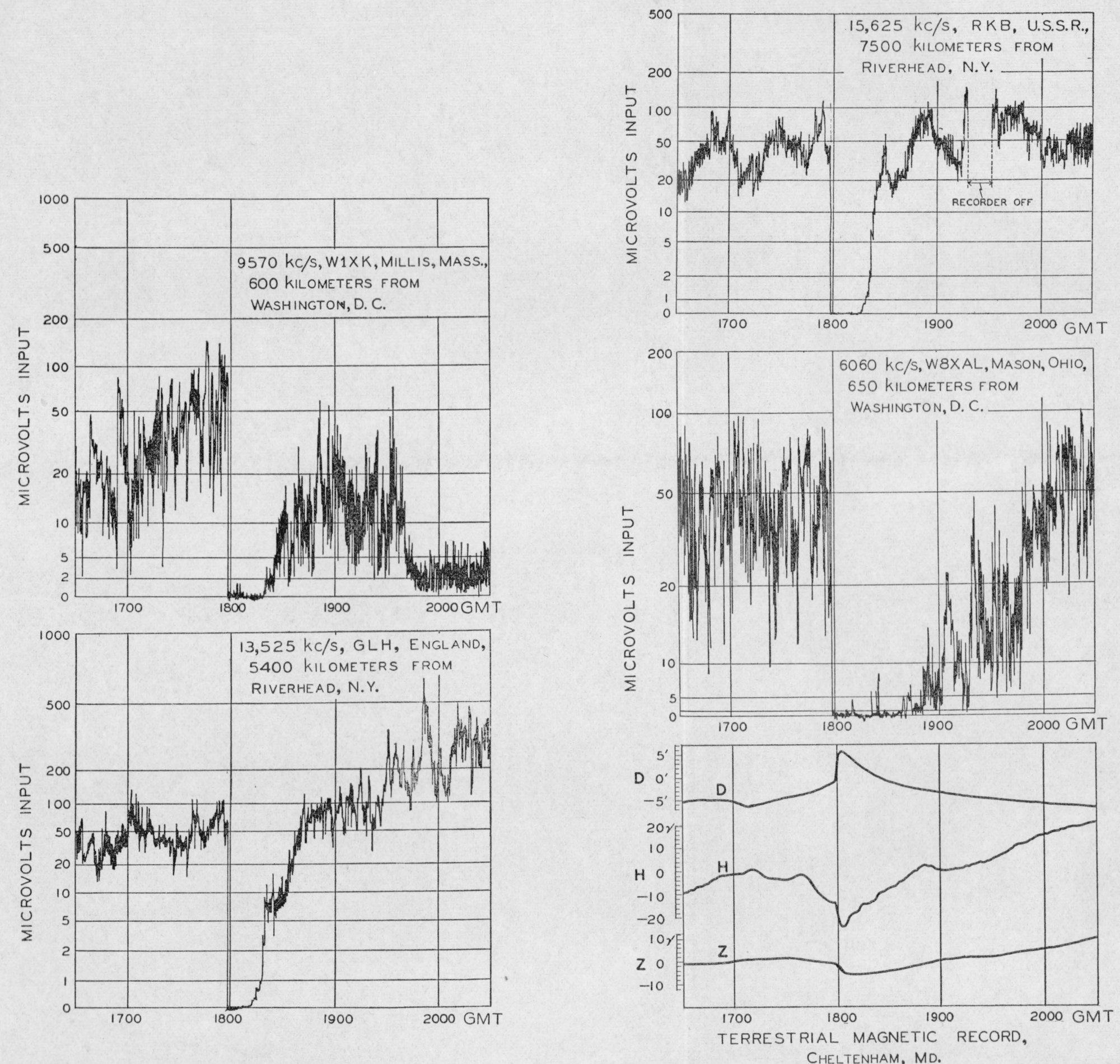

FIGURE 4.-Sudden disturbance of the ionosphere on May 28, 1936, as revealed by radio fadeout and terrestrial magnetic perturbation.

722-37 (Face p. 124) No. 4 

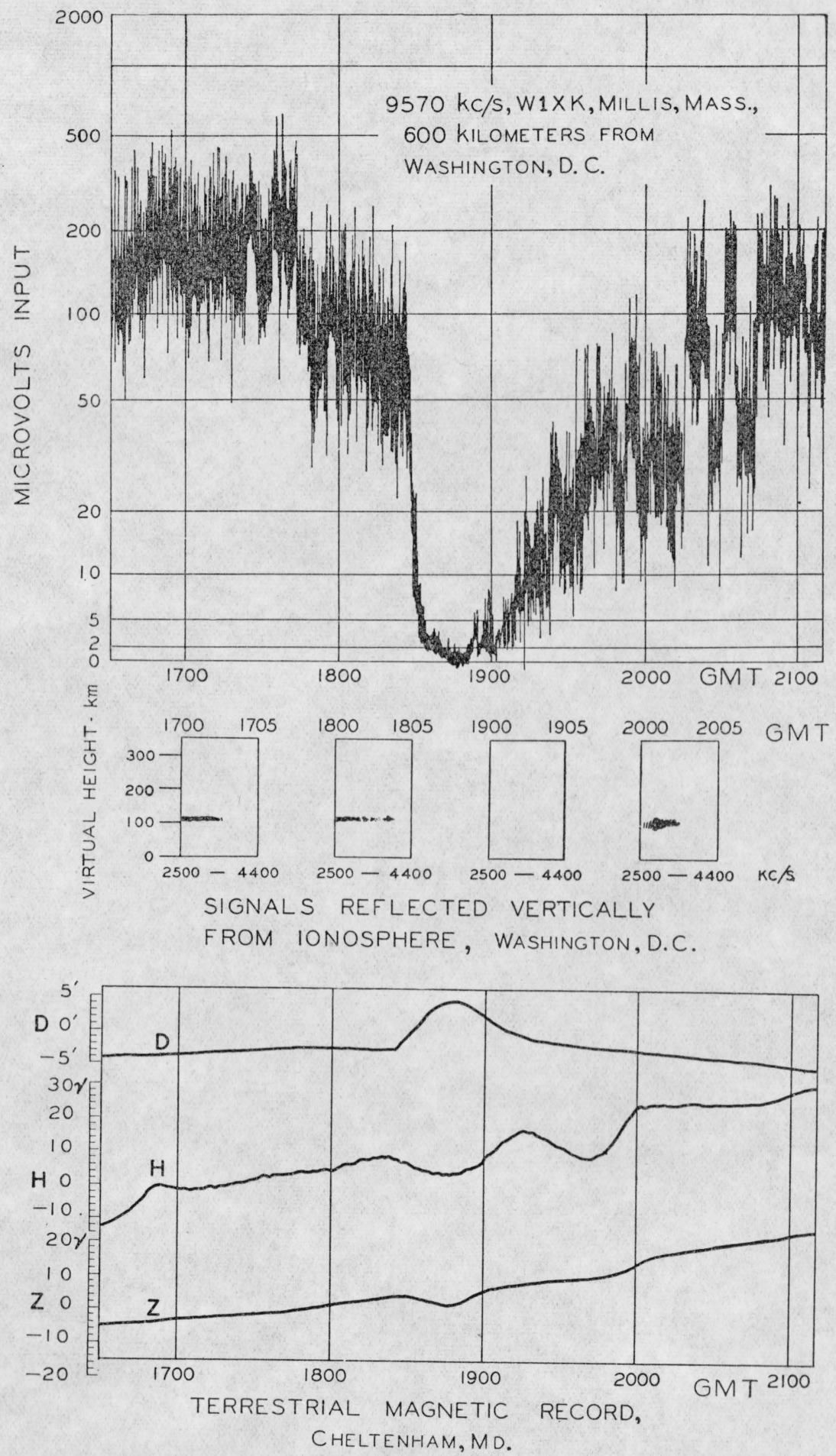

FIGURE 5.-Sudden disturbance of the ionosphere on August 25, 1936, as revealed by radio fadeout and terrestrial magnetic perturbation. 

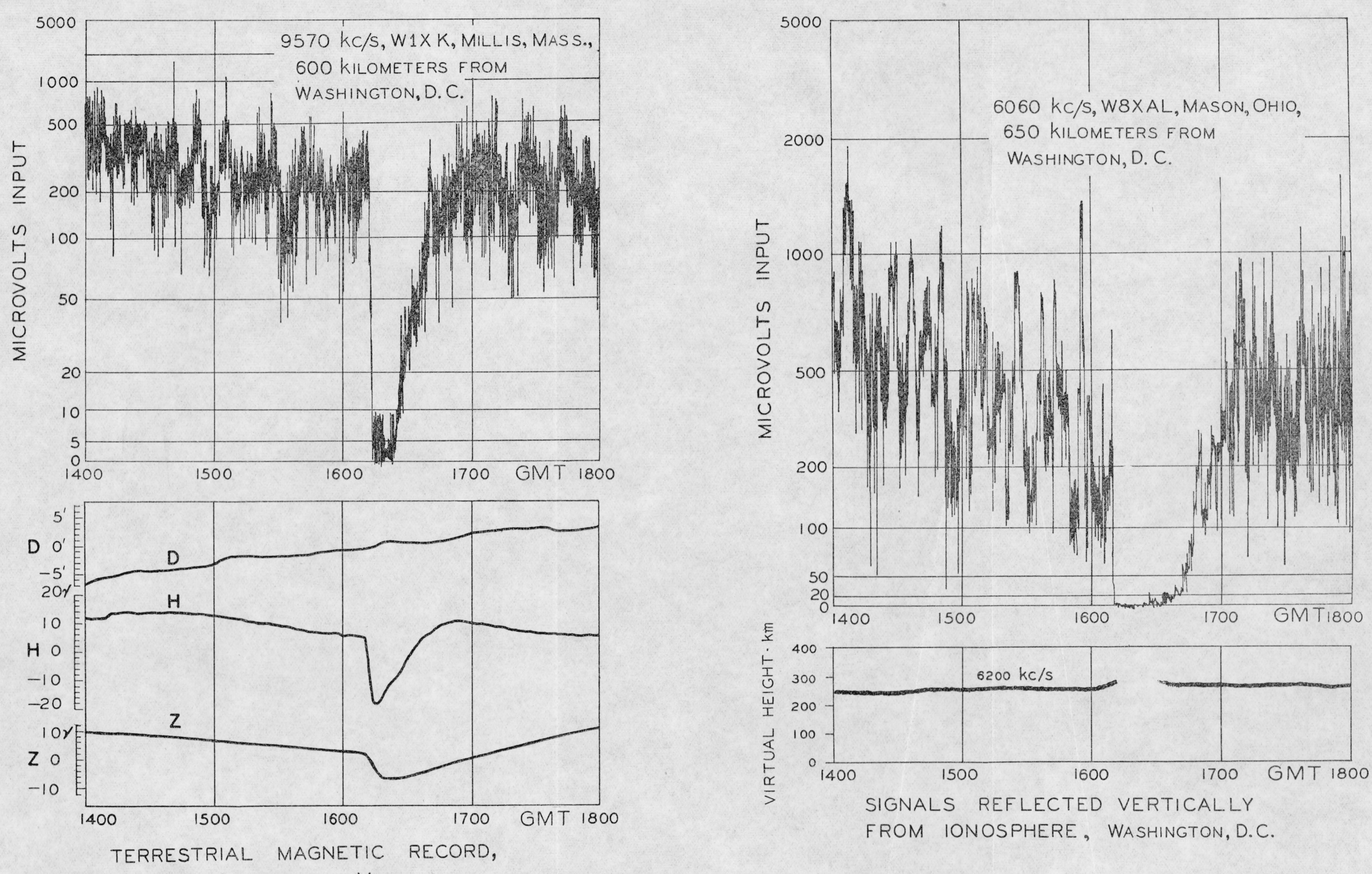

CHELTENHAM, MD.

FIGURE 6.-Sudden disturbance of the ionosphere on November 6,1936 , as revealed by radio fadeout and terrestrial magnetic perturbation. 

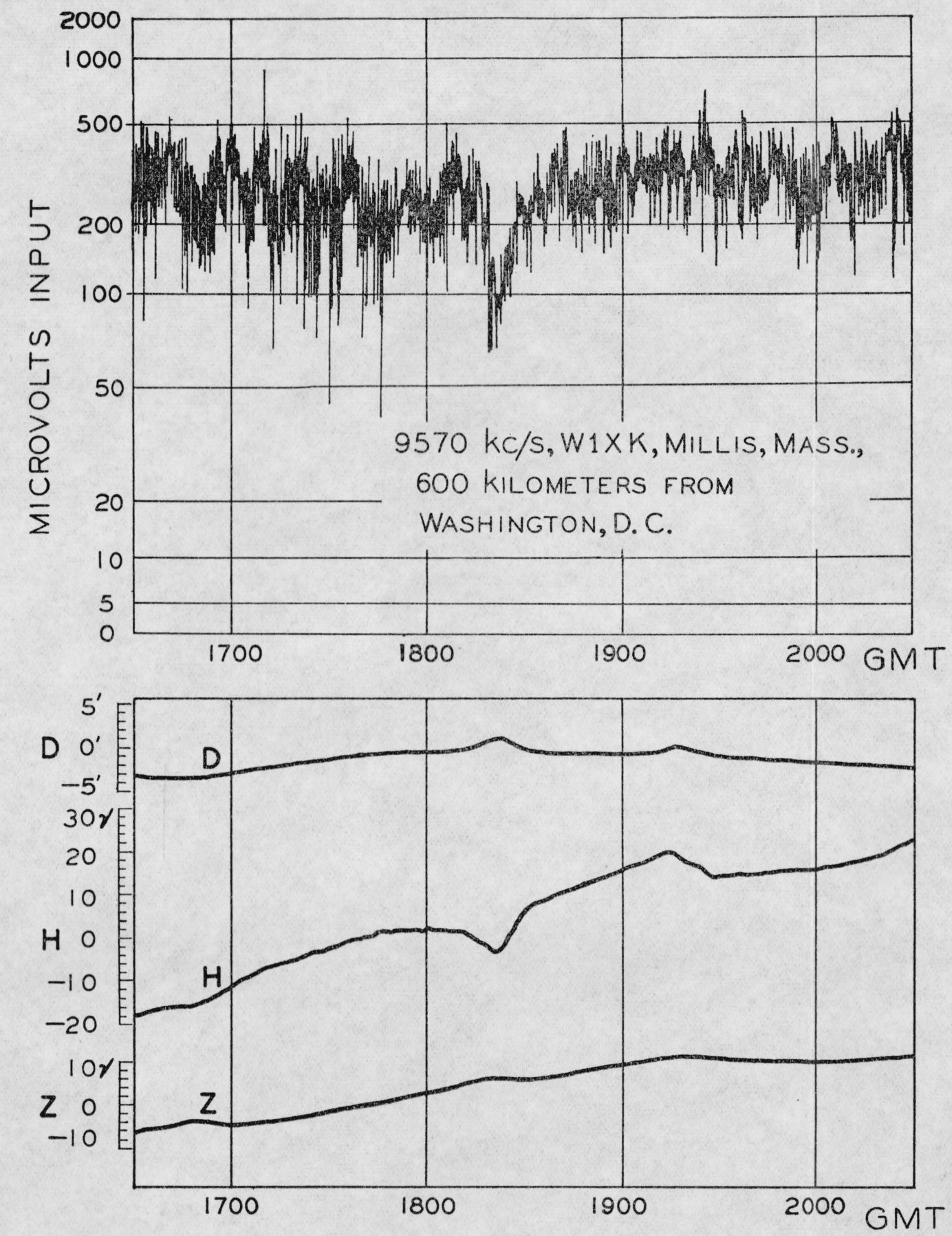

TERRESTRIAL MAGNETIC RECORD,

CHELTENHAM, MD.

FIGURE 7.-Sudden disturbance of the ionosphere on November 8, 1936, as revealed by radio fadeout and terrestrial magnetic perturbation.
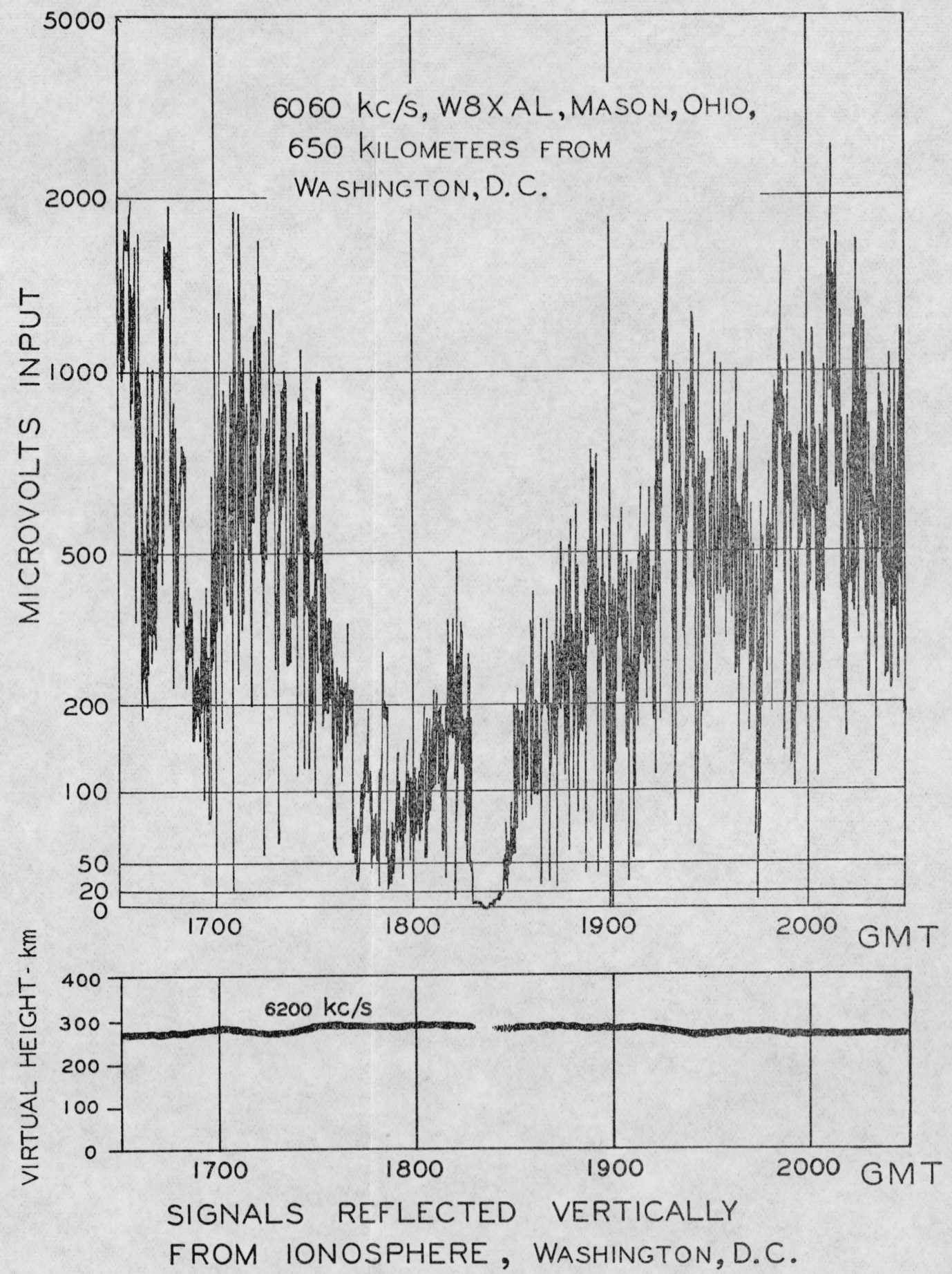

722-37 (Face p. 124) No. 7 

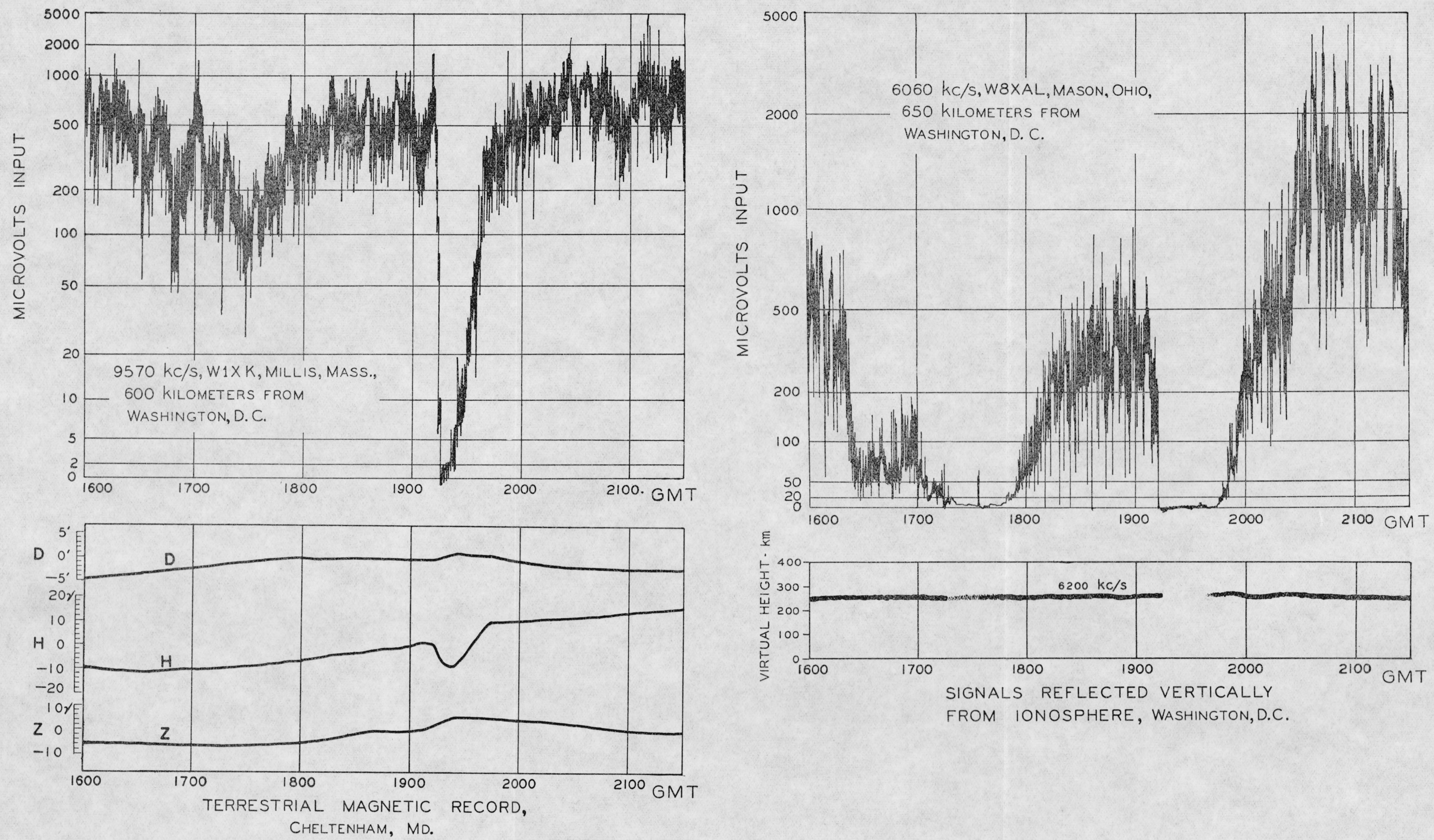

FIGURE 8.-Sudden disturbance of the ionosphere on November 24, 1936, as revealed by radio fadeout and terrestrial magnetic perturbation. 
comprehensive examination of the terrestrial magnetic and earthcurrent records from all observatories has not been made, so these data, like all the others, are decidedly incomplete.

For the terrestrial magnetic and earth-current effects, the times of both beginning and ending as observed at different places are in almost all cases in agreement within about 5 minutes.

The information on the times of the solar eruptions coincident with the other effects was obtained from the Bulletin for Character Figures of Solar Phenomena, published in Zurich, Switzerland, under the auspices of the International Astronomical Union, supplemented by data from R. S. Richardson, of Mt. Wilson Observatory, from the Huancayo Observatory of the Carnegie Institution of Washington, and from R. R. McMath, of Pontiac, Mich.

\section{CHARACTERISTICS OF THE RADIO-TRANSMISSION EFFECTS}

In this section the known facts regarding the effects of the sudden ionosphere disturbances upon radio transmission are summarized. Explanation and theory are given in section VI.

Radio transmission is subject to so many vagaries that it is not surprising that the existence of this particular type of vagary was not recognized until the present investigation. The various vagaries cause large fluctuations in the field intensity received at a distance. These vagaries include such things as fading, abrupt change of general level of intensity due to change of transmission from one ionosphere layer to another, disappearance or appearance of signals because of change of critical frequency at sunrise or other time of day, changes associated with magnetic storms, and "fadeouts." The term "fadeout" is here reserved for the relatively sudden radio effect of the type described in this paper. Each of these kinds of vagary may produce marked diminution of received intensity of radio waves, and in the past they have not been clearly differentiated. A major result of the present research is the demonstration that the fadeout has a number of characteristics which mark it off as a distinct phenomenon.

The data here presented have to do essentially with relatively high frequencies, i. e., above about $1,500 \mathrm{kc} / \mathrm{s}$. The limited information for frequencies below $1,500 \mathrm{kc} / \mathrm{s}$ is mentioned in section III, 4. Ordinarily the intensities of the waves received from radio stations on frequencies below about $1,500 \mathrm{kc} / \mathrm{s}$ are not perceptibly affected during a fadeout. The outstanding and definite effect of a sudden ionosphere disturbance on radio transmission is thus the fadeout observed on frequencies over about $1,500 \mathrm{kc} / \mathrm{s}$.

The fadeouts are characterized by simultaneity of beginning at all places affected, suddenness, very great change of intensity, differing duration and intensity change on different frequencies and at different distances, maximum effect where the sun's radiation is perpendicular, and no effect for all-dark paths. Details of these characteristics follow.

\section{GEOGRAPHIC SIMULTANEITY}

Leaving aside the question of simultaneity of the radio fadeouts with other phenomena (solar, etc.), a distinguishing characteristic of the radio fadeout is the simultaneity of its beginning at the various

$722-37-2$ 
places where it is observed. As shown in table 1, the beginning of a fadeout is in nearly all cases simultaneous within a few minutes. Variations of more than 10 minutes are reported in only 17 of the 118 cases, and these are probably attributable to incompleteness or inaccuracies of observation. It is likely that every fadeout began simultaneously within 3 minutes everywhere, and in many cases the simultaneity was doubtless well within 1 minute.

The time of ending of a fadeout, on the other hand, is very different at different radio frequencies, at different distances, and in different parts of the earth; this is discussed further in sections III, 4, and III, 5.

\section{SUDDENNESS}

The suddenness of the radio fadeouts has astonished many radio observers, operators, and amateurs. Radio signals being received at normal intensity suddenly begin to diminish and the intensity falls to zero, usually within a minute. The effect is on some occasions preceded by a short period of unusually violent fading, echoes, and noise (of a type different from atmospherics), but the effect usually comes without warning. There is sometimes also a period of violent fading, echoes, and noise (different from atmospherics) after as well as before a fadeout.

The suddenness of commencement of a fadeout is vividly illustrated by numerous reports in which the observer stated he thought that the power had gone off in the receiving station, or that a fuse had blown, or that the stations to which he was listening had stopped transmitting, or that his receiving apparatus had developed a sudden fault. Many an observer has dissected his receiving equipment on such occasions in the vain effort to determine why it suddenly went dead.

As may be seen from the examples in figures 1 to 8 , the received radio-wave intensity drops from full value to zero, in most cases within a minute. In some of the more intense fadeouts, like that of February 14, 1936, shown in figure 1, the cutoff occurs within a few seconds. The duration of the effect is greater for the lower frequencies of the frequency range affected; this is discussed further in section III, 4. Sometimes the drop to zero is not quite so sudden for the higher frequencies as for the lower; this is illustrated in figure 6 (Nov. 6, 1936) and figure 8 (Nov. 24, 1936). In a few rare cases, such as the extra fadeout at 1715 , November 24, 1936, shown in figure 8 , the drop to zero was gradual, lasting 10 minutes or so; such a case was not one of the more intense fadeouts, and was not accompanied by a terrestrial magnetic effect.

\section{DEGREE OF INTENSITY CHANGE}

The sudden change of intensity in a fadeout is very great. In most fadeouts, there is a certain band of radio frequencies throughout which the intensity drops from normal value to zero. Sometimes the intensity does not drop all the way to zero for the higher frequencies; see for example figure 7 (Nov. 8, 1936). There is evidence that there is often a frequency limit above which radio transmission is merely weakened rather than reduced to zero, and sometimes a still higher limit above which radio-transmission intensity is not perceptibly reduced. Such is not always the case, however, for sometimes the sky wave intensity is reduced to zero throughout the entire high-frequency radio spectrum. 
The sudden reduction of the intensity to zero when a fadeout occurs is an extraordinary experience. Not only does the radio station appear to stop transmitting, but in the more intense fadeouts even the background noise due to atmospherics "static" disappears. The impression of the observer is that reception goes dead. This enhances the effect of the suddenness of the fadeout and further impels the observer to look for trouble in his receiving equipment.

\section{FREQUENCIES AFFECTED}

The data on radio fadeouts indicate that they occur on all the high frequencies used for long-distance radio work, i. e., from about 1,500 to $30,000 \mathrm{kc} / \mathrm{s}$. Reports are available on radio reception at lower frequencies during many of the fadeouts, and in nearly all cases they indicate that reception was not affected. Some automatic records made by the National Bureau of Standards indicated that the sky wave at broadcast frequencies was weakened during a fadeout. As the ground wave plays a large part in daytime transmission at broadcast and lower frequencies, and the ground wave is unaffected by ionosphere phenomena, fadeout effects would not be prominent and would tend to escape notice. In a very few cases there have been reports of a changed character of fading on broadcast or lower frequencies, or, very rarely, of an increase of intensity on the lower frequencies. Dr. R. Bureau, of France (see Reference, p. 141), has found tbat recorders of atmospherics on frequencies between 27 and $40 \mathrm{kc} / \mathrm{s}$ show an increase in numbers of atmospherics pulses recorded during many of the fadeouts; the times of such occurrences are given in table 1 .

For the frequency range in which fadeout effects are conspicuousi. e., from about 1,500 to $30,000 \mathrm{kc} / \mathrm{s}$ - the effects are greater on the lower frequencies. This is true in regard to the duration of the effects and the degree of intensity change. The variation of intensity change with frequency is described in section III, 3 . The variation of the duration of a fadeout with frequency is illustrated in figures 1 to 8 .

As shown in the figures, the beginning of a fadeout is simultaneous on all frequencies. This simultaneity is exact in most cases, and where not exact the times of beginning seldom differ more than 2 or 3 minutes and the effect occurs first on the lower frequencies. As also shown conspicuously in the figures, the duration or time of ending of a fadeout is very different on different frequencies. The time during which the received intensity is zero, and the time of recovery to normal intensity, are both greater the lower the frequency, other factors being the same. Interpretation of the variation of the effect with frequency in particular cases is complicated by the variation of the effect (discussed in next section below) with geographic location of the radio-transmission paths affected, and also by the variation with distance of transmission. Since, in long-distance transmission, the waves travel a much longer path through the lower ionosphere, the effects are greater for long distances than for short distances. Thus, a fadeout for a long-distance transmission path, on a given frequency, will have a greater reduction of intensity and a greater duration than for a short-distance transmission path. Expressed otherwise, the fadeout effects for a long-distance path correspond to those at a lower frequency for a short-distance path. Bearing this 
in mind, the variation of fadeout effects with frequency is consistent in the figures and in all known fadeouts. H. A. G. Hess reported that during the intense fadeout of Nov. 6, 1936, which happened to occur during a time when long-distance transmission on $40,000 \mathrm{kc} / \mathrm{s}$ was possible, there was no diminution in transatlantic reception on about that frequency. This fadeout was not as intense as some others. As far as known, during the most intense fadeouts all high-frequency sky waves fail.

It is found, and it is consistent with the foregoing conclusion, that fadeouts which last longer are usually observed up to higher frequencies than those of shorter duration; where the duration is short, the higher frequencies are less affected. This is illustrated by a comparison of figure 1 and figure 7 .

\section{GEOGRAPHIC DISTRIBUTION}

All of the fadeouts known to date, listed in table 1, have the characteristic discovered by the author in 1935 for the fadeouts then known, that they occur throughout the hemisphere illuminated by the sun and not in the dark hemisphere. More precisely stated, whenever a radio fadeout occurs some part of the radio-transmission path is in the daylight hemisphere. The continuous automatic recorders of the National Bureau of Standards, recording the field intensities of domestic stations and the normal-incidence ionosphere reflections, have detected no fadeouts between sunset and sunrise. Since many other observers throughout the world have been watching for the effects, the lack of any reports whatever of disturbances on all-dark paths may be taken as proof of their nonoccurrence. For many of the times when radio fadeouts were reported, there have also been specific reports from the dark hemisphere that radio transmission was unaffected. Sometimes a fadeout is reported as observed at a place where it is dark, but in every such case the fadeout occurs only on radio transmission paths which are partly in the hemisphere illuminated by the sun. Thus, fadeouts have in a few cases been observed at midnight in certain places, without violating this principle. Conspicuous examples are: Argentina, 0400 GMT April 2, 1936; California, 0728 GMT May 28, 1936; England, 0016 GMT July 31, 1936.

A study has been made to determine more specifically the variation of intensity of the effect with latitude, longitude, and direction. It is found that the effects are most pronounced in localities where the sun's radiation is perpendicular to the earth's surface. Thus they are most intense in the equatorial regions and diminish with increasing latitude. Similarly, they are most intense at longitudes where it is noon and diminish in both directions toward longitudes where it is night. These relations are true in respect to the suddenness of beginning of the radio fadeout, the time it lasts, the upper limit of frequency affected, and the degree of reduction of field intensity. A fadeout which, at the place where the sun's radiation is perpendicular, may be very intense and prolonged, may, for the same frequency, be a mere brief reduction of field intensity near the boundary of the illuminated hemisphere.

Variations with direction have not been completely analyzed, but they appear to be consistent with the foregoing relations. For example, at receiving points in the United States, reception from stations 
in the southern hemisphere usually exhibits greater effects than reception from other directions (because of passing the equatorial regions). Similarly, a disturbance occurring in the morning usually exhibits greater effects in reception from the east than from the west, and vice versa for the afternoon (because of passing the region where it is noon).

Interpretation of particular cases is complicated by the variation of the effect with the radio frequency and distance.

\section{CHARACTERISTICS OF THE TERRESTRIAL MAGNETIC AND EARTH-CURRENT EFFECTS}

In this section the known facts regarding the effects of the sudden ionosphere disturbances upon terrestrial magnetism and earth currents are summarized. The phenomena are explained in section VI.

In many respects the terrestrial magnetic and earth-current effects have the same characteristics as the radio transmission effects. These similar characteristics include geographic simultaneity, suddenness, limitation of occurrence to the illuminated hemisphere, and the same variation of intensity of effect with latitude and longitude. They are similar also in being only one among the many types of vagaries of terrestrial magnetism and earth currents, such as diurnal and seasonal variations, irregular fluctuations, and magnetic storms (i. e., times of violent magnetic fluctuation). Also, as in radio, the effects due to the sudden ionosphere disturbances have in the past not been recognized as something different from the other classes of vagaries; this study has shown that they have characteristics which mark them off as a distinct and separate type of magnetic perturbation.

\section{LIMITATION TO ILLUMINATED HEMISPHERE}

The data on terrestrial magnetism in table 1 are based principally on the magnetograms of the Cheltenham, Md., Observatory of the U. S. Coast and Geodetic Survey. These magnetograms were examined for the times of all the radio fadeouts. In a few cases data were available from the records of other observatories. In the more intense fadeouts, magnetic effects occurred simultaneously everywhere throughout the sun-illuminated hemisphere. In none of them did effects occur in the dark hemisphere.

The data on earth currents are highly fragmentary, as no systematic examination of earth-current records was made. The few entries of earth-current effects in table 1 are based on occasional reports to the author by various collaborators. The phenomena of earth currents and terrestrial magnetism are so closely interrelated that very probably earth-current effects occurred whenever there were perturbations of terrestrial magnetism.

\section{SIMULTANEITY WITH RADIO FADEOUTS}

Typical examples of the terrestrial magnetic effects are shown in figures 1 to 8 , in which a few Cheltenham magnetograms are reproduced. The magnetic pulses, when they occur, are simultaneous with the radio effects, indicating that both are manifestations of an ionosphere change. As indicated in the table, the magnetic pulses occurred during many of the radio fadeouts but not all. The suddenness and the duration of the pulses may be judged from figures 1 to 8 . 


\section{GEOGRAPHIC DISTRIBUTION}

The geographic distribution of intensity of the terrestrial magnetic effects is, so far as the limited data indicate, the same as for the radio fadeouts. That is, they are most pronounced in the vicinity of that region of the earth's surface to which the sun's radiation is perpendicular, and diminish to zero near the boundary of the illuminated hemisphere. Thus the effects are greatest at low latitudes, and at longitudes where it is noon. They do not commonly occur in the night hemisphere.

\section{COMPARISON WITH MAGNETIC STORMS}

The geographic distribution of intensity of the effects is strikingly different from that of terrestrial magnetic and earth-current effects hitherto known. For example, a world-wide magnetic storm is characterized by a "sudden commencement", a pulse which is simultaneous over the whole earth. The magnetic storms and their sudden commencements thus differ markedly from the magnetic effects associated with sudden ionosphere disturbances in respect to distribution in longitude, since the latter occur only in the sun-illuminated hemisphere.

The two phenomena differ even more extraordinarily in respect to their distribution in latitude. Magnetic storms have minimum effects at the equator and maximum effects near the magnetic poles, just the opposite of the effects of sudden ionosphere disturbances. An interesting consequence of this is that the magnetic and earth-current pulses due to the sudden ionosphere disturbances are much more striking when observed in equatorial regions than in high latitudes. They may be of the same order of magnitude as the fluctuations caused by magnetic storms in equatorial regions, relatively small in middle latitudes, and negligible in high latitudes.

Besides these differences in the geographic distribution of the effects, magnetic storms and the sudden ionosphere disturbances differ in duration, the former lasting hours or days instead of the brief period of the latter.

A study has been made to determine whether there is any relation between times of occurrence of magnetic storms and the sudden ionosphere disturbances. None has been found, and the occurrence of each appears to be quite random with respect to the other. Sudden ionosphere disturbances usually occur during magnetically quiet times, but some occur during magnetic storms. In studying this subject, caution should be observed to consider the results observed at a number of different locations in order to be sure that an apparent effect of the sudden type really is one. Observations of the effect at a single location are often hard to distinguish from other types of vagaries.

One of the major results of this research is the discovery of a separate type of terrestrial magnetic disturbance, with remarkable characteristics which clearly differentiate it from magnetic storms or any previously known types of magnetic perturbations. This is analogous to the discovery of the fadeout as a distinct type of radio vagary. 


\section{SOLAR PHENOMENA ASSOCIATED WITH SUDDEN IONOSPHERE DISTURBANCES}

In this section the known facts regarding solar phenomena having a bearing on the sudden ionosphere effects are summarized. Explanation and discussion follow in section VI.

\section{EXACTNESS OF SIMULTANEITY}

The times of the solar eruptions known to have occurred at the times of the sudden ionosphere disturbances are given in the last column of table 1. They were simultaneous in the sense that the reported time of the solar eruption overlapped the time of the sudden ionosphere disturbance.

The times stated for the solar eruptions are in most cases uncertain by many minutes. This is because of difficulties in their observation. They are sometimes seen with difficulty, and the observing astronomer can not be sure when a solar disturbance begins or ends. They are often obtained by photographs which may be taken at intervals of 15 minutes or more, so that the time of a phenomenon indicated by a difference between two successive photographs may be uncertain.

Because of the uncertainties of their observational material, different astronomers adopt different criteria. The conditions of seeing (presence of haze, etc.) are also different at different observatories at any one time. It results that different solar observers differ considerably in the times they report for the beginning and end of solar eruptions. For example, the solar eruption of August 5 listed in the table was reported by Mount Wilson Observatory as ending at 1613 and by Zurich Observatory as ending at 1648. As another example, the eruption listed for August 28 was reported by Zurich Observatory as ending at 1030, and was reported by Greenwich Observatory as still in progress at 1130. Likewise, an eruption was reported by Zurich Observatory as having begun on July 4, 1936, at 1655, and the same eruption was reported by Mount Wilson Observatory as having begun at 1707 . These cases were all major eruptions, more easily visible than most solar eruptions. It is evidently impossible to determine the times of solar changes within a small number of minutes.

The lack of precision of the solar data thus makes it impossible to say how close is the correspondence of times of the solar eruptions and the terrestrial effects. All of the cases listed in table 1 may reasonably be described as simultaneous occurrences within the limits of our knowledge.

\section{PROPORTIONATE NUMBER OF SIMULTANEOUS OCCURRENCES}

Of the 118 ionosphere disturbances listed in the table, 59 (exactly half) are shown to have been coincident in time with solar eruptions. There may have been a much larger proportion than shown. The sun is not under continuous observation and hence it is not known whether a visible solar eruption occurred or not at the time of any ionosphere disturbance for which no solar eruption is reported. Most solar observatories have in the past carried on observations for not more than an hour each day. An arrangement is in effect by which observatories in different parts of the world stagger their times of observation with a view to a continuous watch on the sun. Cloudy weather and other conditions, however, prevent the full attainment of this program. 
On the other hand, however, when we examine the solar records in the Bulletin for Character Figures of Solar Phenomena, we find that many solar eruptions occur when no ionosphere disturbances are known to have occurred. For example, from January to June 1936, the above mentioned bulletin lists 302 solar eruptions, and only 29 of these were simultaneous with known disturbances of the ionosphere. A larger proportion of coincidences is found if we consider only the more intense solar eruptions (those of arbitrary intensities 2 or 3); there were in the same period 69 of these listed, of which 17 were simultaneous with known disturbances of the ionosphere. It is probable that many of the visible solar eruptions were not accompanied by detectable ionosphere disturbances, although the converse may not be true. Many of these eruptions may rise high enough in the solar atmosphere to permit the escape of visible light but not high enough to permit the escape of the ultraviolet radiation responsible for the sudden bursts of ionization in the earth's atmosphere. The use of automatic radio and magnetic recorders continuously has assured knowledge of the occurrence of practically all ionosphere disturbances in the western hemisphere.

\section{CHARACTER OF ERUPTIONS}

The eruptions here discussed are bright chromosphere eruptions. They are visible as sudden increases of brightness of large bright patches on the sun's surface, and when occurring at the limb of the sun are seen as eruptive prominences. An eruption usually, but not always, takes place near an active sunspot group. Most of the eruptions simultaneous with sudden disturbances of the ionosphere are much brighter than the average.

\section{LOCATION OF ERUPTIONS ON SUN}

It is of interest to know whether the eruptions causing sudden ionosphere disturbances occur wholly or predominantly at any particular location on the sun's surface. It might be thought, for instance, that the radiation would be effective only when projected radially from the sun to the earth, i. e., when the eruptive area is in the center of the sun's disk. The solar locality of all the visually observed eruptions simultaneous with sudden ionosphere disturbances is known, and has been examined in this connection. It is found to be random, which means that the eruptions send out their radiations in all directions from the sun's surface; the terrestrial effects occur regardless of where the eruption takes place, near the sun's limb, at or near the center of the disk, or anywhere between.

The locations of the eruptive areas on the sun have also been examined to find out whether particular areas give rise to repeated effects, and especially whether such effects are repeated after one or more rotations of the sun. On a number of occasions, successive eruptions from a given solar area, accompanying sudden ionosphere disturbances, have occurred in the course of a day or two. Little evidence, however, has been found of any repetition of eruptions from a particular area after one or more rotations of the sun. 


\section{RECURRENCE TENDENCY}

A possible periodic tendency in the times of occurrence of the sudden ionosphere disturbance was suggested by the occurrence of the ones first known to the author, and listed first in table 1, at intervals of approximately 55 days. This is shown graphically in figure 9 , in which all the occurrences are plotted. The intensity of each occurrence was weighted on an arbitrary basis, having regard to the duration and magnitude of the effect, the number of places from which reported, etc. The intensities thus weighted by two persons independently agreed very well and were plotted as ordinates on an arbitrary scale in figure 9. The abscissas are time, each

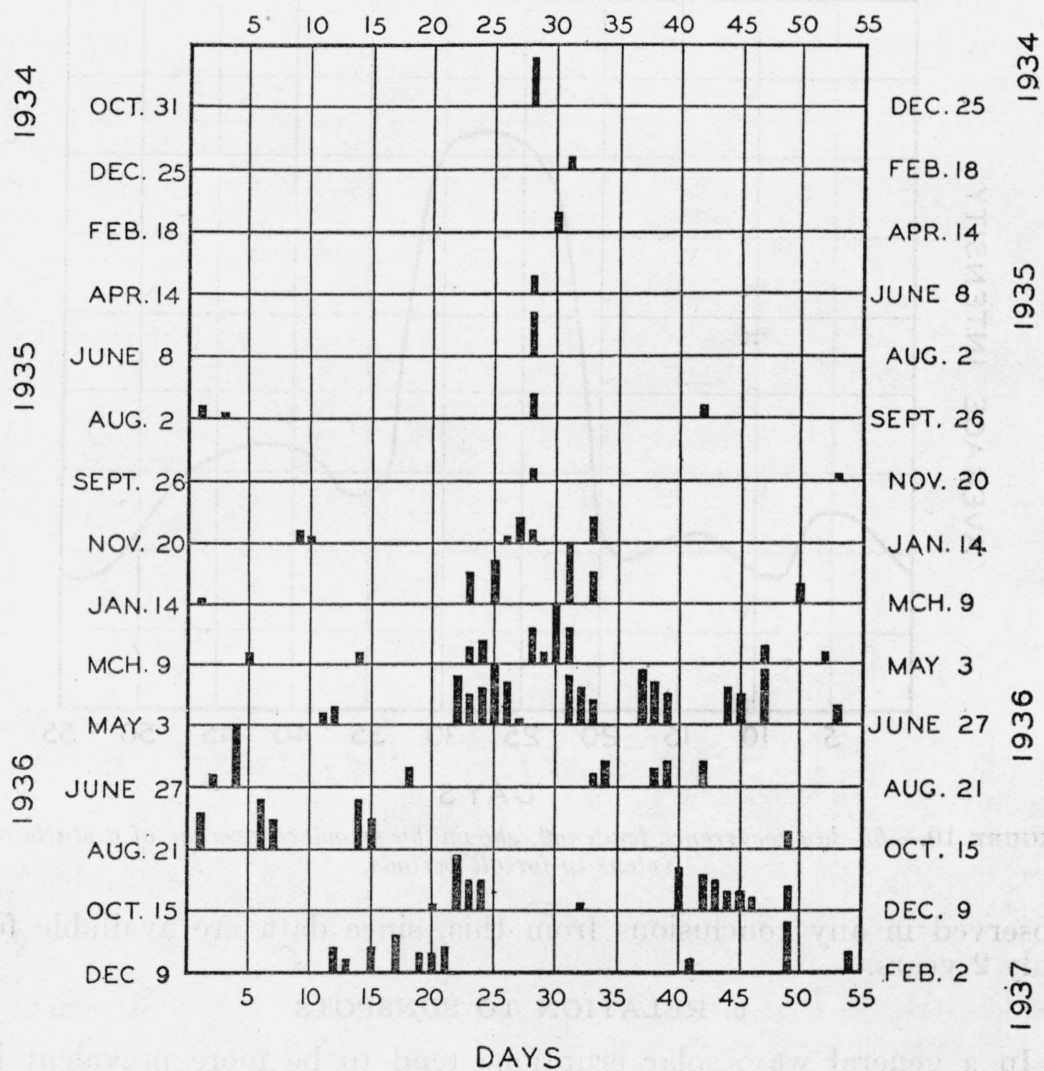

FIGURE 9.-Recurrence diagram of sudden ionosphere disturbances, arranged in 55-day periods; inter sity of disturbance is approximately indicated by ordinate.

horizontal line being an interval of 55 days. In figure 10 is plotted an average curve for all the 55-day periods. The existence of a 55 -day recurrence tendency is indicated. This should not be taken as proved, as 2 years is not considered to be a sufficient time to establish such a tendency with certainty. It may be mentioned that the 55-day recurrence tendency remains very marked even if the first seven cycles, in which it is so pronounced, be disregarded. Further analysis has indicated that the recurrence tendency averages slightly less than 55 days, but it is closer to 55 than 54 . 
It is of interest that there is no indication of a recurrence tendency of the order of 27 days. The sun rotates on its axis in a remarkable way, rotating faster at the equator than elsewhere. The rotation period is about 24 days at the sun's equator and about 36 days near its poles. The average rotation period of the portion of the sun in which the eruptions take place, and also incidentally the period for which terrestrial magnetic disturbances show a recurrence tendency (presumably dependent upon some unidentified type of solar eruptions), is between 27 and 28 days. Thus the tendency to a recurrence period of 55 days, of the ionosphere disturbances, is twice the well-known solar period of approximately 27 days. Again, caution should be

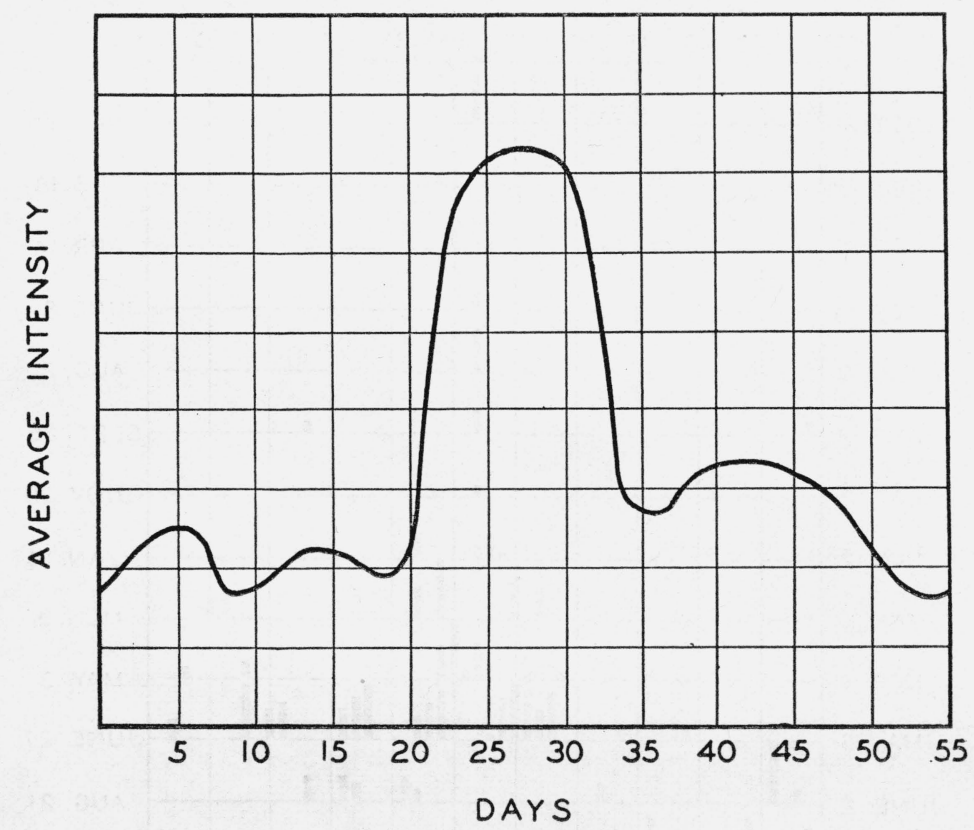

Figdre 10.-55-day recurrence tendency, shown by smoothed average of disturbance intensity for all periods.

observed in any conclusions from this, since data are available for only 2 years.

\section{RELATION TO SUNSPOTS}

In a general way, solar eruptions tend to be more prevalent in years when sunspots are more numerous, and thus their number may be expected to wax and wane in an 11-year cycle with the sunspots. There is no evidence, however, of any short-time correlation with sunspot numbers of the sudden ionosphere disturbances or the particular solar eruptions accompanying them. The number of sudden ionosphere disturbances certainly does not vary from day to day, or from month to month, in accordance with the sunspot numbers. Data are not available over a long enough time to permit a conclusion as to whether there is any correlation of yearly averages. 


\section{DISCUSSION AND EXPLANATION}

The foregoing facts clearly outline a phenomenon which is some type of sudden change somewhere in the ionosphere. Whenever the phenomenon occurs, it is most intense in that region of the earth where the sun's radiation is perpendicular and diminishes to zero at the outer edge of the illuminated hemisphere. Its onset usually occurs within a minute, and is simultaneous throughout the hemisphere affected. Its various effects begin simultaneously, and last from about 10 minutes to several hours, the occurrences of greater intensity in general producing effects of longer duration. The effects include the sudden blotting out of high-frequency radio sky-wave transmission, sudden changes in low-frequency atmospherics, sudden changes in terrestrial magnetic intensities, and sudden changes in earth currents. The effects are markedly different from other types of changes in these quantities. They are more intense where it is noon than where it is other times of the day, and are more intense in equatorial regions than in higher latitudes. The radio effects are very large, indicating that the ionosphere changes producing them are intense ones.

\section{SEAT OF THE DISTURBANCES DEDUCED FROM RADIO EFFECTS}

The various characteristics of the effects summarized in the preceding paragraph and detailed earlier in the paper indicate them to be due to an ionosphere phenomenon; and the nature of that phenomenon is more particularly elucidated by a consideration of the radio effects.

Long-distance radio transmission takes place by means of so-called sky-waves which are reflected back to earth from the ionosphere, i.e., the ionized upper portion of the atmosphere. The ionization is stratified in the daytime into a number of layers, of which three principal layers are well recognized; the $E$-layer, $F_{1}$-layer, and $F_{2}$-layer. The $E$ and $F_{1}$ layers are, respectively, about 120 and $220 \mathrm{~km}$ above the earth's surface, and the $F_{2}$-layer is at a height varying from about 250 to $400 \mathrm{~km}$ at different times. The maximum ionization density is progressively greater from the $E$ to the $F_{2}$ layer. The presence of ionized particles of air makes the layers reflect radio waves which reach them. For a given maximum ionization density and angle of incidence, all radio waves up to a certain frequency are reflected and waves of higher frequency pass through to higher layers. For example, at a given time and distance, all radio frequencies up to 9,000 $\mathrm{kc} / \mathrm{s}$ might be reflected by the $E$-layer, those from 9,000 to $30,000 \mathrm{kc} / \mathrm{s}$ be reflected from the $F_{2}$-layer, and no frequencies above $30,000 \mathrm{kc} / \mathrm{s}$ be reflected at all (i. e., no frequencies above this limit could be received over the distance considered).

An increase in the maximum ionization density of a layer raises the upper limit of frequency of radio waves which it can reflect. During a number of the sudden ionosphere disturbances measurements or recordings were in progress to determine this upper limit of frequency for the several layers, $E, F_{1}$, and $F_{2}$. In no case was an appreciable change observed during or just after the disturbance. (It is possible to speak of radio observations being in progress during a fadeout because there were usually some frequencies, distances, or locations for which radio transmission continued, while for others the radio 
transmission was annihilated-see section III). It may be concluded that the sudden ionosphere disturbances change the maximum ionization density of the $E, F_{1}$, or $F_{2}$ layers either not at all or very slightly.

On the other hand, ionosphere studies have amply proved that an increase in the ionization density of a region through which radio waves pass on the way to being reflected by a higher layer causes an increase in absorption of the radio waves' energy and results in a diminution of the received wave intensity. This is exactly what happens, and, indeed, to a striking degree, during one of the sudden disturbances.

It may therefore be concluded that these sudden disturbances involve a sudden great increase of ionization in some region through which radio waves pass on the way to being reflected by a higher region. Since the fade-out occurs in radio waves reflected by the $E$ as well as the higher layers, the absorbing medium must be below the $E$-layer.

The seat of the sudden large increase of ionization is thus below the $E$-layer, i. e., lower than $120 \mathrm{~km}$ above the earth's surface. The $E$-layer is thus not the lowest part of the ionosphere. This is in harmony with some other facts which have been discovered recently. It is now known that waves of broadcast and lower frequencies are propagated in the daytime at certain seasons by reflection from a layer lower than the $E$-layer. This was discovered ${ }^{5}$ by observation of the changes in the characteristics of received waves near sunset and sunrise, showing a change from $E$-layer at night to a lower layer in the daytime and back to the $E$-layer at night.

This low layer may perhaps be called the $D$-layer. Not enough is yet known about it to be sure that this designation is appropriate. There may be several layers acting, whose combined effect we observe, or one or another of them may predominate at different times. Or the effective layer may more or less merge into the $E$-layer. With our present limited knowledge it is perhaps as well to think tentatively of a single low layer or region in which low-frequency transmission takes place, and in which the sudden ionosphere disturbances occur.

For low frequencies (below about 1,500 kc/s), a sudden ionosphere disturbance does not produce as complete a fadeout as at higher frequencies, because radio waves tend to be reflected by, instead of passing through, the layer in which the sudden increase of ionization occurs. Indeed, the sudden increase of ionization may even tend to increase rather than decrease the very low-frequency radio-wave intensity; this is in harmony with the results of $R$. Bureau on lowfrequency atmospherics (30 to $40 \mathrm{kc} / \mathrm{s}$ ).

For frequencies above about $1,500 \mathrm{kc} / \mathrm{s}$, the ionization of the low layer is ordinarily not great enough to reflect the waves. They pass through and are reflected from the $E$ or higher layers where the ionization density is greater. When the sudden increase of ionization in the low layer occurs, however, the ionization suddenly becomes great enough to produce large absorption of the radio-wave energy and a fadeout occurs. There is less interchange of energy between the ions and the radio waves, the higher the frequency, and therefore for very high frequencies the fadeout effects are less pronounced; this in accordance with experience, as described in section III and illustrated in

\footnotetext{
- Smith and Kirby, Critical frequencies of low ionosphere layers, Phy. Rev. 51, 890 (May 15, 1937).
} 
figures 1 to 8 . It is also clear from this conception why the effects on a given frequency for normal-incidence transmission are the same as the effects on a much higher frequency for grazing-incidence transmission: the waves at grazing incidence travel a much longer path through the abnormally ionized layer and thus experience an added amount of energy interchange with the ions, thus compensating for their higher frequency.

The source of the sudden ionization changes must be outside the earth, and therefore has to come through the $E, F_{1}$, and $F_{2}$ layers. It must have a character, therefore, distinctly different from the source of ionization of those layers. It produces its effect at a level where the air density is great enough to insure numerous collisions of moving ions and hence rapid absorption of the radio-wave energy. The radiation producing this effect is therefore of a type which can penetrate the better known higher layers and produce ionization where the mean free path is shorter than at the higher levels. The effect must be produced by a very sudden burst of very penetrating radiation, which reaches and ionizes a level of the atmosphere where the air density is great enough to insure rapid recombination of the ions as well as rapid absorption of the energy of radio waves reaching such region. This explains the great reduction of the radio-wave intensity and the short duration of the effect, as well as the suddenness of the drop of radio intensity.

The recombination proceeds so fast that the ionization and the ionizing energy are probably very nearly in equilibrium at all times. As the ionizing radiation from the sun dies out, in accordance with the disappearance of the solar eruption, the intense ionization in the lower ionosphere wanes, and the highest radio frequencies affected are soon freed of its effects. As the ionization diminishes, lower and lower frequencies recover from the effects. The duration of a fadeout at a given frequency is probably dependent not only on the intensity of the burst of ionizing energy but also on the duration of the solar eruption.

\section{MAGNETIC EFFECTS}

The occurrence of the sudden ionization being thus inferred and explained from the radio effects, it is clear why simultaneous changes are sometimes observed in terrestrial magnetism and earth currents. Both of the latter phenomena are due in part to the motion or drift of ions in the earth's atmosphere, constituting in the aggregate vast currents whose associated magnetic field constitutes a portion of the earth's magnetism and whose fluctuations account for the variations in terrestrial magnetism and earth currents. When a sudden ionosphere disturbance of the type here considered takes place, the sudden increase in ionization permits a simultaneous sudden change in net current flowing and thus perturbations in terrestrial magnetism and earth currents. It is to be noted that such perturbations do not depend entirely on the amount of the ionization, as do the radio effects, but involve also drift or motion of the ions. The radio effects are therefore not always accompanied by magnetic and earth-current perturbations. Whether the latter become observable or not depends on the complicated circumstances of the earth's magnetism at various places and times. When observed, they share the characteristics of the radio effects and the acting cause in the ionosphere, i. e., simul- 
taneity throughout the portion of the earth affected, absence in the dark hemisphere, suddenness, and maximum intensity where the sun's radiation is perpendicular.

As previously stated, this type of perturbation of terrestrial magnetism and earth currents is strikingly different from the perturbations associated with "magnetic storms." Radio effects have shown that during magnetic storms the ionization density of the highest layer of the ionosphere $\left(F_{2}\right.$ layer) is reduced and the ionization is diffused rather than sharply stratified. These effects thus prove that at least part of the phenomena of magnetic storms have their seat in the $F_{2}$ layer. ${ }^{678}$

It has here been shown, on the other hand, that the sudden ionosphere disturbances have their seat below the $E$-layer, and the phenomena causing the terrestrial magnetic and earth-current perturbations associated therewith must therefore also have their seat below the $E$ layer.

Thus the two kinds of magnetic phenomena arise in entirely different portions of the ionosphere, in entirely different ways, and are probably due to ionizing agents of different characteristics. We thus have a new tool for analysis of the characteristics of terrestrial magnetism and for determination of their causes. There has hitherto been little known as to the locations of the vast ionosphere current systems which cause the fluctuations of terrestrial magnetism. The new possibility of localizing the levels in which different types of perturbations originate will aid in deciding between rival theories of terrestrial magnetism and should do much to bring to light the hitherto unknown mechanisms of terrestrial magnetic variations.

\section{SOLAR SOURCE}

The sun is in an extremely turbulent state, and on it occur frequent eruptions from which are emitted radiations having a great range of wave lengths. There is no reason to doubt that some of the radiations from some of these eruptions are the sudden bursts which cause the sudden disturbances of the ionosphere of this planet. This is strongly indicated by the numerous observations of such eruptions and ionosphere disturbances coinciding in time.

The lack of occurrence of an ionosphere disturbance during every visible solar eruption does not at all vitiate the idea of a causal relation, because many different kinds of radiation are emitted in solar eruptions and visible radiation is not the kind which affects the ionosphere. The existence of visible solar effects during the solar cataclysms which cause the ionosphere disturbances is fortuitous. The simultaneous occurrence of an ionosphere disturbance and the flare of light which makes the solar eruption visible indicates that the radiation causing the ionosphere disturbance travels to earth with the velocity of light. As shown above, the radiation which causes the sudden large increase of ionization of a low region of the ionosphere is of a very penetrating type; it is therefore electromagnetic radiation of frequency far above visible light.

o S. S. Kirby, T. R. Gilliland, E. B. Judson, and N. Smith. The ionosphere, sunspots, and magnetic storms. Phys. Rev. 48, 849 (1935).

I S. S. Kirby, T. R. Gilliland, N. Smith, and S. E. Reymer. The ionosphere, solar eclipse, and magnetic

storms. Phys. Rev. 50, $258(1936)$
'S. S. Kirby, N. Smith, T. R. Gilliland, and S. E. Reymer. The ionosphere and magnetic storms. Phys. Rev. 51, 992 (1937). 
This doubtless gives the explanation why not all visible solar eruptions cause ionosphere disturbances. Evidently some eruptions emit the particular type of radiation which penetrates to the region below the $E$ layer and ionizes it, and some do not.

The ionosphere disturbances and their associated effects are the only known means of detecting the causative solar radiation, because this radiation can not penetrate the relatively dense lower atmosphere and reach the earth's surface and thus can not be directly detected by any instrumental means. We have thus come into possession of a means of studying a new class of invisible solar radiation, not hitherto accessible to detection or measurement.

The results of this research prove conclusively that ultraviolet radiation from the sun can cause terrestrial magnetic fluctuations. Dr. E. O. Hulbert has advocated similar ideas in numerous papers during the past 10 years.

Ionosphere phenomena should be of very great value in increasing our knowledge of the sun. The ionization phenomena of the $F_{2}$ layer are decidedly different from those of the $E$ layer, and there may thus be differences in the causative radiations for the two layers. Certain effects in the $F_{2}$ layer, associated with magnetic storms, may be caused by a different type of radiation. As we have seen, the radiation causing the sudden ionosphere disturbances is of still different character. All of these classes of radiation can be studied only by their ionosphere effects, as they do not penetrate down to the earth's surface. Ionosphere phenomena, as detected by radio, terrestrial magnetic, and earth-current effects, thus become the unique means by which we can study various classes of radiation from the sun.

The physical nature of the sun is extremely interesting and presents many mysteries. One of the chief mysteries is the eruptions. Little is known about the precise relation of the eruptions to sunspots or about the cause of either. The sun is a rotating sphere of very hot gas, and a sunspot is a vortex resulting from a great cataclysmic change in a portion of the sun. A sunspot lasts from a few days to a few months. The sudden eruptions, usually lasting only a few minutes, commonly occur during the early stages of a neighboring sunspot group; they may be connected with the process which gives birth to sunspots. This process is thought by astronomers to be the sudden formation of vast quantities of helium from hydrogen by the combination of four hydrogen atoms to form one of helium, with great energy liberation. Determination of the wave lengths of the radiation accompanying sudden pulses which occur during this process should aid in further identifying its nature and the obscure cause within the sun. Such determination is among the possibilities of future study of the sudden ionosphere disturbances. The duration of some of the phenomena during eruptions may also be learned through this study.

Another aspect of the sudden ionosphere disturbances, which is worthy of study in connection with solar phenomena, is the time grouping of the disturbances. As shown in figure 9, the major disturbances showed a very marked 55-day recurrence tendency from November 1934 to May 1936, then in May and June 1936, there was an extraordinary outburst of them, after which there were relatively few of them for several months.

A study of the solar circumstances of the eruptions accompanying such disturbances, and the possible future determination of the wave 
lengths of the solar radiation associated with them, may eventually elucidate the nature of the eruptive processes within the sun and the causes of sunspots.

The work here reported has been in large measure a world-wide cooperative study. Many individuals and organizations have sent me reports of their observations of various aspects of the sudden disturbances of the ionosphere as they occurred.

The most consistent source of data has been the continuous records of field intensity of high-frequency stations, and the records of ionosphere phenomena, made by my colleagues in the National Bureau of Standards, S. S. Kirby, N. Smith, T. R. Gilliland, and S. E. Reymer.

Dr. R. Jouaust, of the Laboratoire Central de Radioélectricité, France, and the author have regularly interchanged data during this study. Dr. Jouaust has compiled and distributed comprehensive bulletins of data on the radio fadeouts, principally as observed in Europe. These were forwarded from the French National Committee to the other National Committees of the International Scientific Radio Union, and this service is being continued.

The Carnegie Institution of Washington has collaborated in the supplying of solar and terrestrial magnetic data. In particular, Dr. R. S. Richardson, of the Mount Wilson Observatory, California, has cooperated with the author through the supplying of information monthly on solar eruptions.

The Coast and Geodetic Survey has assisted by supplying copies of its daily magnetograms made at its terrestrial magnetic observatory at Cheltenham, Md.

Regular reports on radio fadeouts as observed during the handling of radio-communication traffic have been furnished by:

H. H. Beverage, chief research engineer, RCA Communications Inc.

H. Pratt, chief engineer, Mackay Radio and Telegraph Co.

L. Espenschied, Bell Telephone Laboratories.

N. Koomans, chief, Staatsberdreijf der P. T. T., Holland.

T. Nakagami, chief engineer, Kokusai-Denwa Kaisha Ltd., Japan.

Reports have been furnished on particular radio fadeouts and related phenomena by many others, including:

Chief Signal Officer, War Department, U. S. A.

Naval Communication Service, U. S. A.

Aeronautical Radio Inc., U. S. A.

British Broadcasting Corporation, England.

W. Calloway, Office of Posts and Telegraphs, Kuala Lumpur, Malaya.

J. H. McMullin, Commissioner of Police, British Columbia, Canada.

C. P. Edwards, Department of Transport, Ottawa, Canada.

Reports on numerous radio fadeouts have been supplied by many radio amateurs, forwarded through the American Radio Relay League. Of these, the reports of F. D. Jenkins, of Atlanta, Ga., have been particularly helpful.

\section{BIBLIOGRAPHY}

J. H. Dellinger. A new cosmic phenomenon. Science 82, 351 (Oct. 11, 1935).

J. H. Dellinger. A new radio-transmission phenomenon. Phys. Rev. 48, 705 (Oct. 15, 1935).

J. H. Dellinger. Confirmation of cosmic phenomenon. Science 82, 548 (Dec. $\left.6, \frac{\pi}{3} 1935\right)$. 
J. H. Dellinger. New radio-transmission phenomenon. QST 19, p. 21 of Dec. 1935.

J. H. Dellinger. A new solar radio disturbance. Electronics 9, 25 (Jan. 1936).

R. S. Richardson. The hydrogen outburst on the sun and radio fading. Science

83, 6 supp. (Jan. 10, 1936).

J. H. Dellinger. New cosmic phenomenon. QST 20, p. 8 of Jan. 1936.

R. S. Richardson. Sunspot activity and radio-transmission fadeouts. Trans. Amer. Geophys. Union, part I, 172 (1936).

J. H. Dellinger. High-frequency radio fadeouts continue. QST 20, p. 37 of June 1936.

R. S. Richardson. The bright hydrogen eruption and radio fadeout of April 8, 1936. Ter. Mag. \& Atmos. Elec. 41, 197 (June 1936).

O. W. Torreson, W. E. Scott, H. E. Stanton. A conspicuous solar eruption on April 8, 1986, and simultaneous disturbances on magnetic, ionospheric, and earthcurrent records at Huancayo magnetic observatory. Ter. Mag. \& Atmos. Elec. 41, 199 (June 1936).

G. Leithäuser. On abnormal upper-atmospheric ionization on Feb. 14, 1986. Funktech. Monatsheft 2, 241 (July 1936).

D. Arakawa. Abnormal attenuation in short radio-wave propagation. Report of Radio Research in Japan 6, 31 (1936).

K. Ohno, M. Nakagami, and K. Miya. On the fall of short-wave intensity of short duration. (In Japanese.) J. Inst. Elec. Engrs. (Japan) p. 938 (August 1936).

A. M. Braaten. Fadeout observations at Riverhead, N. Y. T. \& R. Bul. (London) 12, 111 (Sept. 1936).

M. Waldmeier. The great solar eruption of Aug. 28, 1936. Naturwiss. 24, 638 (Oct. 2, 1936).

R. S. Richardson. The bright eruption and radio fadeout of August 25, 1936. Pub. Astron. Soc. Pacific 48, 278 (Oct. 1936).

The ionosphere; the Dellinger wipe-out. T. \& R. Bul. (London) 12, 214 (Nov. 1936)

R. Bureau and J. Maire. Ionospheric anomalies of sudden onset. Compt. rend. 203, 1257 (Dec. 7, 1936).

H. W. Newton. Radio fadings and bright solar eruptions. Nature 138, 1017 (Dec. 12, 1936).

J. H. Dellinger. Direct effects of particular solar eruptions on terrestrial phenomena. Phys. Rev. 50, 1189 (Dec. 15, 1936).

R. Jouaust, R. Bureau, and L. Eble. The probable causes of sudden fadeouts of short radio waves and their relation to magnetic phenomena. Compt. rend. 203, 1534 (Dec. 28, 1936).

J. A. Fleming. Notes on radio fadeout of August 25, 1936. Ter. Mag. \& Atmos. Elec. 41, 404 (Dec. 1936).

O. W. Torreson, W. E. Scott, F. T. Davies, and H. E. Stanton. A solar eruption on November 6, 1936, and disturbances in earth's magnetism, earth-currents, and the ionospheric regions. Ter. Mag. \& Atmos. Elec. 41, 409 (Dec. 1936).

D. Arakawa. Abnormal attenuation in short radio-wave propagation (Second Report). Report of Radio Research in Japan 6, 169 (1936).

Solar eruptions and radio fadeouts. Nature 139, 61 (Jan. 9, 1937).

R. Bureau. Abnormalities of the ionosphere and bright solar eruptions. Nature 139, 110 (Jan. 16, 1937).

J. H. Dellinger. Radio fadeouts through 1936. QST 21, p. 35 of Feb. 1937.

A. G. McNish. Magnetic effects associated with bright solar eruptions and radio fadeouts. Nature 139, 244 (Feb. 6, 1937).

J. H. Dellinger. Sudden ionospheric disturbances. Ter. Mag. \& Atmos. Elec. 42, 49 (March 1937).

F. T. Davies, O. W. Torreson, W. E. Scott, and H. E. Stanton. A solar eruption of November 27, 1936, and simultaneous disturbances in earth's magnetism, earthcurrents, and the ionospheric regions. Ter. Mag. \& Atmos. Elec. 42, 93 (March 1937).

H. A. G. Hess. Observations on the Deliinger-effect on November 6, 1986. Funktech. Monatsheft 3, 74 (March 1937).

Washington, May 26, 1937. 